\title{
THERMOGALVANIC CORROSION OF ALLOY 31 IN DIFFERENT HEAVY BRINE LiBr SOLUTIONS
}

Fernández-Domene, R.M., Blasco-Tamarit, E., García-García, D.M., GarcíaAntón, J. *
Ingeniería Electroquímica y Corrosión (IEC). Departamento de Ingeniería Química y
Nuclear. ETSI Industriales. Universidad Politécnica de Valencia. P.O. Box 22012, E-
46071 Valencia. Spain. Tel.34-96-387 76 30, Fax.34-96-387 76 39, e-mail.jgarciaa@iqn.upv.es

Thermogalvanic corrosion generated between two electrodes of Alloy 31, a highlyalloyed austenitic stainless steel (UNS N08031), has been investigated imposing different temperature gradients in three deaerated $\mathrm{LiBr}$ solutions, under open circuit conditions by using a zero-resistance ammeter (ZRA). Besides EIS spectra were acquired in order to explain the obtained results. On the whole, cold Alloy 31 electrodes were anodic to hot Alloy 31 electrodes, since an increase in temperature favoured the cathodic behaviour of the hot electrode. Thermogalvanic corrosion of Alloy 31 in the LiBr solutions studied was not severe, although it negatively affects the corrosion resistance of the cold anode. The protective properties of the passive film formed on the anode surface were found to improve with thermogalvanic coupling time.

Keywords: A. Stainless steel; B. EIS, polarization; C. Passive films 


\section{INTRODUCTION}

Most vapour compression systems commonly use CFCs refrigerants, because of their thermophysical properties. However, the use of CFCs is banned or extremely restricted, and HCFCs, although are less damaging to the ozone layer, will be also prohibited globally by 2040 (Montreal Protocol, 1988). Absorption technology which uses aqueous lithium bromide solutions as working fluid appears to be a promising alternative to vapour-compression. Having zero ozone depletion and global warming potentials, absorption systems are completely friendly to the environment [1-6]. Moreover, these systems are heat-powered and need very little electricity.

Nevertheless, $\mathrm{LiBr}$ solutions attack the equipment material during normal operation conditions. Therefore, many corrosion problems take place inside the absorption refrigeration units, decreasing the operating efficiency and leading to safety problems [1,6-13]. One method to solve these corrosion problems is to develop high corrosion resistant materials. Austenitic and duplex stainless steels are commonly used as structural components in absorption machines [1,13,14], but failures in form of pitting corrosion are sometimes observed in the hottest parts of the system. High-alloyed austenitic stainless steels, such as Alloy 31, present greater amounts of alloying elements, namely chromium (Cr), molybdenum (Mo) and nickel (Ni), as compared with the established $18 \% \mathrm{Cr}, 10 \% \mathrm{Ni}$ baseline steels, showing higher corrosion resistance than conventional stainless steels.

The existence of zones with different temperatures inside the absorption machines can aggravate the corrosion problems of the construction materials, giving rise to a type of corrosion known as thermogalvanic corrosion. Thermogalvanic corrosion is a form of 
galvanic action that results from the action of a macrocouple formed when different pieces of the same metal immersed in an electrolyte have different temperatures. The piece of metal that forms the anode in such a macrocouple becomes corroded, providing some degree of protection to the piece of metal that behaves as a cathode. It has been shown [15-17] that the extent of thermogalvanic corrosion depends, among others, on the potential difference between the cold and hot electrodes, the electrical conductivity of the solution, the distance between the electrodes and the overvoltages of the anode and cathode processes. The original definition of thermogalvanic corrosion was made under the assumption that the electrode reactions were the reverse of each other, so the oxidizing agent which was reduced at the cathode was then regenerated at the anode $[18,19]$. This definition restricts the use of the term to reversible electrodes and excludes subsequent changes which may occur at either electrode as a result of a continued current flux (e.g. the formation of a passive film on the anode surface), so it is not suitable. Thus, in practice, any enhanced corrosion as a consequence of the apparition of a temperature gradient between different zones of the same metal is regarded as thermogalvanic corrosion [20-23].

The importance of thermal gradients in contributing to corrosion of industrial equipment has been reported in numerous studies [17,23-30]. Thermogalvanic corrosion resulting from temperature gradients can cause the early failure of copper pipes exposed to a sustained temperature gradient. Most of the work that has been done on this subject demonstrates that large temperature differences between sections of copper metal can cause serious corrosion problems [24-26]. Other works have been directed at heat exchangers materials $[27,28]$. Several authors have noted thermogalvanic corrosion as a 
corrosion mechanism within pressurized water nuclear reactor steam generators (SGs) [29,30], as well as in supercritical water oxidation reactors [17].

The aim of the present investigation is to determine the thermogalvanic corrosion behaviour of a highly alloyed austenitic stainless steel (Alloy 31) immersed in $\mathrm{LiBr}$ solutions and submitted to different temperature gradients.

\section{EXPERIMENTAL PROCEDURE}

\section{Materials and specimen preparation}

The material tested was the highly alloyed austenitic stainless steel Alloy 31 (UNS N08031: $26.75 \% \mathrm{Cr}, 31.85 \% \mathrm{Ni}, 1.50 \% \mathrm{Mn}, 0.10 \% \mathrm{Si}, 6.60 \% \mathrm{Mo}, 1.21 \% \mathrm{Cu}, 31.43 \%$ Fe, $0.002 \% \mathrm{~S}, 0.017 \% \mathrm{P}, 0.005 \% \mathrm{C}, 0.193 \% \mathrm{~N}$ ), provided by ThyssenKrupp VDM. Alloy 31 electrodes were cylindrically shaped (8-mm diameter and $55 \mathrm{~mm}$ long) and covered with a polytetrafluoroethylene (PTFE) coating. The exposed area to the solution was $0.5 \mathrm{~cm}^{2}$. All specimens were wet abraded from $500 \mathrm{SiC}$ (silicon carbide) grit to $4000 \mathrm{SiC}$ grit, and finally rinsed with distilled water.

The samples were tested in $400 \mathrm{~g} / \mathrm{l}(4.61 \mathrm{M}), 700 \mathrm{~g} / \mathrm{l}(8.06 \mathrm{M})$ and $992 \mathrm{~g} / \mathrm{l}(11.42 \mathrm{M})$ LiBr solutions, prepared from $\mathrm{LiBr}(98$ wt.\%), from PANREAC.

Thermogalvanic corrosion behaviour (open circuit measurements)

The open circuit measurements were performed by using the potentiostat as a zeroresistance ammeter (ZRA). The electrochemical cell employed to carry out 
thermogalvanic corrosion tests, which has been designed by the authors, consisted of two half cells (Figure 1). Each half cell was thermostated separately so that the temperature of one half cell was $T_{1}\left(25^{\circ} \mathrm{C}\right)$, whereas that of the other half cell, $T_{2}$, varied between $25,50,75$ and $100^{\circ} \mathrm{C}$ (when using the $400 \mathrm{~g} / \mathrm{l} \mathrm{LiBr}$ solution, the maximum temperature was $75^{\circ} \mathrm{C}$, since at $100^{\circ} \mathrm{C}$ the solution showed signs of boiling). The reference electrode $(\mathrm{Ag} / \mathrm{AgCl} 3 \mathrm{M} \mathrm{KCl})$ was immersed in the cold compartment during the open circuit measurements and a deaerated atmosphere was created by purging $\mathrm{N}_{2}$ over the electrolyte solution. Both compartments were separated by a sintered glass disc (porosity 3). This separator serves as a thermal and diffusional barrier between the half cells, which prevents the hot and cold electrolytes from mixing and over which the stable temperature gradient occurs [20,31-35]. Besides, the use of this glass membrane or a salt bridge over the region of the temperature gradient diminishes the so-called thermal liquid junction potential (TLJP) to a small value, and prevents this potential from varying with time, so that the TLJP does not affect the thermogalvanic potential value [36]. However, this separation of the two half cells by the sintered disc produced an internal resistance of 5-10 $\Omega$, depending on the temperature of the cell. This value is lower than that obtained by other authors working with sintered glass membranes $[20,31]$, so the internal resistance introduced by the sintered glass membrane is acceptable.

Alloy 31 samples were coupled through the Autolab PGSTAT302N potentiostat used as a ZRA, and both the potential and the current density of the thermogalvanic couple were recorded every $0.5 \mathrm{~s}$. for 6 hours. The current sign was positive when the direction of the electrons was from working electrode 1 (WE1) to working electrode 2 (WE2), that is, when WE1 was corroding. Current values were negative when the electrons flowed 
in the opposite direction. The tests were designed with the cold electrode (at $25^{\circ} \mathrm{C}$ ) as WE1 and the hot electrode (at $25,50,75$ and $100^{\circ} \mathrm{C}$ ) as WE2.

\section{EIS measurements}

The EIS measurements were made with the Autolab PGSTAT302N potentiostat, before and after the 6 hours of open circuit measurements (ZRA) at the open circuit potential value, in order to study the effect of the thermogalvanic couple on the electrolyte/metal interface. The voltage perturbation amplitude was $10 \mathrm{mV}$, in the frequency range of 100 $\mathrm{kHz}$ to $10 \mathrm{mHz}$. The conditions of EIS experiments were the same as those in ZRA tests.

\section{RESULTS AND DISCUSSION}

\section{Thermogalvanic corrosion}

Open circuit measurements (ZRA)

The data of thermogalvanic potentials and thermogalvanic current densities versus time have been studied in the $400 \mathrm{~g} / \mathrm{l}, 700 \mathrm{~g} / \mathrm{l}$ and $992 \mathrm{~g} / \mathrm{l} \mathrm{LiBr}$ solutions, imposing different temperature gradients (from $25^{\circ} \mathrm{C}$ to $75^{\circ} \mathrm{C}$ in the $400 \mathrm{~g} / \mathrm{L} \mathrm{LiBr}$ solution and to $100^{\circ} \mathrm{C}$ in the rest of solutions), by using the potentiostat as ZRA. Figure 2 shows, as an example, the thermogalvanic potential and current density data of the pair Alloy 31 (at $25^{\circ} \mathrm{C}$ ) Alloy 31 (at $75^{\circ} \mathrm{C}$ ), in the three $\mathrm{LiBr}$ solutions under study. The positive sign of thermogalvanic current density indicated that the cold electrode was the anode of the pair in these tests at $25^{\circ} \mathrm{C}-75^{\circ} \mathrm{C}$. In the $992 \mathrm{~g} / \mathrm{l} \mathrm{LiBr}$ solution, after the second hour of 
thermogalvanic coupling, a polarity reversal took place and the hot electrode became the anode, as it will be explained below.

There was a general tendency for the thermogalvanic current density to decrease during the immersion time, as the anode of the pair passivated by oxide film growth $[11,21,37-$ 40]. Besides, in all the $\mathrm{LiBr}$ solutions, thermogalvanic potential shifted towards less negative values with time, which also meant an improvement in the protective properties of the passive film formed on the anode surface $[11,39,41]$. The most remarkable characteristic of a passive system undergoing uniform corrosion is to present very frequent voltage and current density transients, but with quite low amplitudes [11,42,43], like those registered in Figure 2 . The magnitude of thermogalvanic current density experienced very low oscillations, lower than 0.2 $\mu \mathrm{A} / \mathrm{cm}^{2}$ during all the test, indicating that the anode of the pair was in the passive state $[11,43]$.

Figures 3 and 4 show the mean values of thermogalvanic current density $\left(i_{t h m}\right)$ and potential $\left(E_{t h m}\right)$, respectively, registered between the thermogalvanic couple formed by the pair hot Alloy 31 - cold Alloy 31 electrodes during each hour of the test. It can be seen from Figure 3 that the values of $i_{\text {thm }}$ were very small, lower than $0.2 \mu \mathrm{A} / \mathrm{cm}^{2}$ in all the cases, which evidences the development of a passive film on the anode surface that made the current flow difficult [41].

For the $400 \mathrm{~g} / \mathrm{l} \mathrm{LiBr}$ solution, the cold electrode was the anode in all the experiments, since values of $i_{\text {thm }}$ were positive during the $6 \mathrm{~h}$ of the test. Several authors have also obtained cold anodes when studying other thermogalvanic systems $[21,22,26]$. Besides, 
the anodic nature of the cold electrode was favoured as temperature in the hot half-cell raised, since $i_{\text {thm }}$ values increased (Figure 3a). It has been reported that temperature has a marked influence on the cathodic branch of the polarisation curves for Alloy 31 in heavy brine $\mathrm{LiBr}$ solutions $[44,45]$. Therefore, these results could be explained by this effect that temperature had on the cathodic branch of the polarisation curves. Thus, in spite of the fact that the passive film formed on the cold electrode surface (anode) was more protective than on the hot electrode (cathode) [13,44-54], the enhancement of the cathodic reaction with temperature seems to prevail on determining the polarity of the thermogalvanic pair.

For the $700 \mathrm{~g} / \mathrm{l} \mathrm{LiBr}$ solution the cold electrode was the anode of the thermogalvanic couple and a raise in temperature favoured this anodic behaviour (or the cathodic behaviour of the hot Alloy 31electrode), since the values of $i_{t h m}$ recorded increased with temperature (Figure 3b), the same as in the $400 \mathrm{~g} / \mathrm{l} \mathrm{LiBr}$ solution.

For the $992 \mathrm{~g} / \mathrm{l} \mathrm{LiBr}$ solution, the hot electrode was the anode of the pair up to the $25^{\circ} \mathrm{C}$ $50^{\circ} \mathrm{C}$ test. In the test performed at $25^{\circ} \mathrm{C}-50^{\circ} \mathrm{C}$, current density values are lower than at $25^{\circ} \mathrm{C}-25^{\circ} \mathrm{C}$, which evidences the formation of a more protective passive film at $50^{\circ} \mathrm{C}$. In the test done at $25^{\circ} \mathrm{C}-75^{\circ} \mathrm{C}$, the cold electrode was the anode during the first two hours of immersion, but then there was a polarity reversal and the hot electrode became the anode of the pair (Figure 3c). In the test carried out at $25^{\circ} \mathrm{C}-100^{\circ} \mathrm{C}$, a similar polarity reversal took place at the end of the fifth hour of coupling (Figure 3c). The influence that temperature had on the cathodic reaction $[44,45]$ made the hot electrode be the cathode of the thermogalvanic pair during the first hours of the tests. However, when the passive film formed on the anode (cold electrode) was enough protective, a polarity 
reversal took place and the hot electrode became the anode of the pair until the end of the tests. Therefore, in these cases, the higher protectiveness of the passive film formed on the cold electrode surface prevailed over the positive effect that temperature had on the cathodic reaction on establishing the final polarity of the thermogalvanic pair. Other authors have reported changes in the polarity of the electrodes with time due to the intervention of passive film formation [21,22,25,41,55]. In the $992 \mathrm{~g} / \mathrm{l} \mathrm{LiBr}$ solution, when the hot Alloy 31 electrode behave as the anode of the thermogalvanic pair in the test performed at $25^{\circ} \mathrm{C}-100^{\circ} \mathrm{C}$ (within the sixth hour of experiment), current density values were higher than in the other tests, indicating worse protective properties of the passive film formed on the hot electrode at $100^{\circ} \mathrm{C}$, since temperature favours the kinetics of corrosion reactions, and more specifically, the anodic dissolution of the metal $[40,41]$.

It is worth noting that the polarity of the tests performed without temperature gradient (i.e. $25^{\circ} \mathrm{C}-25^{\circ} \mathrm{C}$ ) is not important at all. This polarity is exclusively due to very small differences in the surface characteristics between both electrodes, since the material composition (Alloy 31), temperature and $\mathrm{LiBr}$ concentration were exactly the same in both half-cells. These tests with no temperature gradient were carried out in order to obtain the cell potential value at $\Delta \mathrm{T}=0$ and to determine the Seebeck coefficient of the thermogalvanic system (see the following section).

The previous results regarding thermogalvanic current densities recorded during the tests show that thermogalvanic corrosion rates were rather low in all the experimental conditions of the present study, since $i_{t h m}$ values were very small. However, this kind of corrosion will remain as long as temperature differences exist, i.e. during the whole 
operating period of the absorption plant. Thus, thermogalvanic corrosion represents a dormant situation that can accelerate corrosion if the environment changes, e.g. a local increase in temperature or bromide concentration.

Concerning the thermogalvanic potential, its values became less negative with immersion time for the three $\mathrm{LiBr}$ solutions under study (Figure 4), which evidences the formation and growth of a passive film on the anode surface $[11,39,41]$. The $E_{t h m}$ values also increased with temperature in all the $\mathrm{LiBr}$ solutions. According to Ashworth and Boden [20] an increase of the thermogalvanic potential with temperature is indicative of a cold anode, since temperature favoured the cathodic behaviour of the hot electrode, making its corrosion potential be more positive than that of the cold electrode.

Thermogalvanic potentials and Seebeck coefficient

The electromotive force $(e m f)$ of a thermogalvanic cell (thermogalvanic potential, $E_{t h}$ ) has four main contributions $[17,56,57]$ :

$$
E_{t h}=\Delta \Phi_{M}+\Delta \Phi_{T L J P}+\Delta \Phi_{T D}+\Delta \Phi_{M 1-M 2}
$$

where $\Delta \Phi_{M}$ is the Metal/solution potential (Galvani potential) difference (that changes with temperature), $\Delta \Phi_{T L J P}$ is the thermal liquid junction potential (TLJP), $\Delta \Phi_{T D}$ is the thermal diffusion potential (due to the Soret effect) and $\Delta \Phi_{M 1-M 2}$ is the potential difference as a consequence of the metallic thermocouple between the electrodes and the measuring instrument. 
In most systems, the thermocouple effect is relatively small $[17,36,56,58]$ (of the order of tens of $\mu \mathrm{V} /{ }^{\circ} \mathrm{C}$ ). In practice, potential differences due to the Soret effect (because of the apparition of a thermal diffusion gradient) are also very small $[17,56,57]$, especially when diffusion processes between both half-cells are impeded [59], as in the present work with the use of a sintered glass membrane, which makes diffusion and ionic migration difficult; consequently, concentration gradients due to temperature gradients will not take place in this system, or they will appear after very long times. The TLJP on the border of the hot and cold electrolyte can make a significant contribution to the emf, especially in the case of acidic electrolyte $[17,56,60]$, although in neutral solutions, the TLJP is small [56]. In addition, the use of the sintered glass membrane as a separator between both compartments can reduce, to a small value, the TLJP. On this basis, the first contribution in equation (1), that is, the changes of metal/solution potentials (Galvani potentials) with temperature can be regarded as a guide to the behaviour of a thermogalvanic cell [56].

Equation (1) can be derived with respect to the system temperature, $T$, obtaining:

$$
\frac{\partial E_{t h}}{\partial T}=\frac{\partial \Delta \Phi_{M}}{\partial T}+\frac{\partial \Delta \Phi_{T L J P}}{\partial T}+\frac{\partial \Delta \Phi_{T D}}{\partial T}+\frac{\partial \Delta \Phi_{M 1-M 2}}{\partial T}
$$

or in a simpler way:

$$
\frac{\partial E_{t h}}{\partial T} \equiv E_{t h}^{\prime}=\Phi_{M}^{\prime}+\Phi_{T L J P}^{\prime}+\Phi_{T D}^{\prime}+\Phi_{M 1-M 2}^{\prime}
$$


The temperature coefficient of the thermogalvanic cell, $E_{t h}^{\prime}$, is known as Seebeck coefficient, by analogy with thermoelectric phenomena [61-64], and can be determined from the slope of the $E_{t h}$ vs $\Delta T$ representation, according to:

$$
E_{t h}=\frac{\partial E_{t h}}{\partial T} \cdot \Delta T+E_{0}=E^{\prime} \cdot \Delta T+E_{0}
$$

where $E_{o}$ is the cell potential when there was no temperature gradient $(\Delta \mathrm{T}=0)$. Seebeck coefficients provide the sensitivity of the thermogalvanic cell emf (thermogalvanic potential) to a variation of the temperature gradient present in the system. Thus, the higher the value of the Seebeck coefficient (in absolute value), the smaller the variation in temperature gradient required to generate large potential differences between the electrodes, and the more prone the metal to undergo thermogalvanic corrosion.

Figure 5 shows the diagrams of $E_{t h}$ vs $\Delta T$ for the three LiBr solutions studied (namely 400, 700 and $992 \mathrm{~g} / \mathrm{LiBr}$ ), where $E_{t h}$ was the thermogalvanic potential obtained after the 6 hours of thermogalvanic coupling, when the system reached a steady state. The graph shows typical results of experimental measurements of Seebeck coefficients in thermogalvanic cells in this temperature range $[31,57,58,65,66]$. It can be seen from this figure that for all three $\mathrm{LiBr}$ solutions, the $E_{t h}-\Delta T$ pairs are straight lines, which means that the emf of the thermogalvanic cell, that is, the thermogalvanic potential $E_{t h}$, depends linearly on the temperature. Moreover, according to Kasap [62], if the Seebeck coefficient is positive, electrons diffuse from the cold zone to hot zone. Thus, the positive Seebeck coefficients (positive slopes) obtained in this study indicate that the hot electrode of the cell was the cathode of the thermogalvanic pair $[31,58,62]$. 
As it can be observed from Figure 5, Seebeck coefficients, whose values are approximately $3 \mathrm{mV} /{ }^{\circ} \mathrm{C}$, seem not to depend on $\mathrm{LiBr}$ concentration, within the concentration range investigated. Other authors $[57-59,66,67]$ have obtained a decrease in Seebeck coefficient with increasing concentrations in their respective thermogalvanic systems, although Szabó and Holeschovsky [57,58] have found that in $\mathrm{CuSO}_{4}$ solutions of higher concentration than 6.4 wt.\% (in the present study, $\mathrm{LiBr}$ solutions have concentrations higher than 31 wt.\%), the value of Seebeck coefficient did not depend on electrolyte concentration and remained constant. Therefore, the effect of the concentration dependence of any of the parameters in equation (3) on $E_{t h}^{\prime}$ is negligible. Particularly, if $\Phi_{T D}^{\prime}$ does not depend on the electrolyte concentration, $\Phi_{T D}$ will not be concentration dependant either, and the contribution of $\Phi_{T D}$ to the $E_{t h}$ value will be negligible, as well. This affirmation is consistent with the explanations given above concerning the thermal diffusion potential (due to Soret effect) when defining the thermogalvanic potential in equation (1).

\section{EIS measurements}

EIS spectra

The characterization of Alloy 31/electrolyte interface was done through EIS measurements carried out before and after the 6 hours of thermogalvanic coupling, for the three $\mathrm{LiBr}$ solutions studied (400, 700 and $992 \mathrm{~g} / \mathrm{l} \mathrm{LiBr})$, at different imposed temperature gradients (Figures 6, 7 and 8). In all the cases, the EIS diagrams exhibit a typical passive state shape characterized by high impedance values with non-ideal capacitive behaviour, suggesting that a highly stable film formed on all the electrodes 
surface [68-71]. For the tests performed at $25^{\circ} \mathrm{C}-25^{\circ} \mathrm{C}$ the EIS spectra was the same for both cold and hot electrodes before thermogalvanic coupling.

For the $400 \mathrm{~g} / \mathrm{l} \mathrm{LiBr}$ solution, the anode of the thermogalvanic pair was always the cold electrode (Figure 3a). Figure 6 shows the EIS diagrams (in form of Nyquist and Bodephase representations) for the $400 \mathrm{~g} / \mathrm{l} \mathrm{LiBr}$ solutions, at the three different temperature gradients $\left(25^{\circ} \mathrm{C}-25^{\circ} \mathrm{C}, 25^{\circ} \mathrm{C}-50^{\circ} \mathrm{C}\right.$ and $\left.25^{\circ} \mathrm{C}-75^{\circ} \mathrm{C}\right)$ for both cold and hot Alloy 31 electrodes, before and after the thermogalvanic coupling (BTC and ATC, respectively).

As it can be seen from EIS plots in Figure 6, both electrodes had higher Faradic impedance after the 6 hours of test for all the temperature gradients. Moreover, in the Bode-phase representation it is observed that the capacitive behaviour of both electrodes is also better after the thermogalvanic coupling, so the characteristics of passive films formed on the electrodes surface improved with immersion time, as reported in literature [72-74]. These facts are especially significant for the cold electrode, which was the anode of the thermogalvanic coupling. For the hot electrode (the cathode of the pair), the improvement of the passive film characteristics after the thermogalvanic coupling was far less significant than for the cold electrode (anode). Thus, the passive film formed on the anodic member of the pair during the 6 hours of test developed better protective properties than that formed on the cathode surface. It is noteworthy that at $25^{\circ} \mathrm{C}-75^{\circ} \mathrm{C}$, two time constants are perfectly discernible from Bode-phase plots.

For the $700 \mathrm{~g} / \mathrm{l} \mathrm{LiBr}$ solution, the anode of the thermogalvanic pair was always the cold electrode (Figure 3b). Figure 7 shows the Nyquist and Bode plots for the pair cold 
Alloy 31 - hot Alloy 31 in the $700 \mathrm{~g} / \mathrm{L} \mathrm{LiBr}$ solution before and after the thermogalvanic coupling.

In the Nyquist and Bode diagrams depicted in Figure 7, an increase in the low frequency limit of the impedance after the 6 hours of thermogalvanic coupling is observed for both electrodes. Besides, the Bode-phase diagrams also show a tendency to a more capacitive behaviour at the low frequency limit with immersion time, which suggests an improvement in the protective properties of the passive film formed on the electrodes surface [72-74]. These changes in the EIS spectra after the thermogalvanic coupling were more significant for the anode of the pair than for the cathode, in a similar way as in the $400 \mathrm{~g} / \mathrm{l} \mathrm{LiBr}$ solution. Nevertheless, for the temperature gradient of $25^{\circ} \mathrm{C}-50^{\circ} \mathrm{C}$, this trend was not followed. In the test performed at $25^{\circ} \mathrm{C}-50^{\circ} \mathrm{C}$, the impedance response of the hot electrode (which was the cathode during the whole test) was somewhat better than that of the cold electrode (which was the anode). Thus, despite the fact that the cold electrode was the anode of the pair, the passive film formed on its surface was slightly less protective than the passive film formed on the hot electrode (cathode). This fact can be explained in terms of thermogalvanic current density values. Although mean current density values in this test were positive (Figure 3b), which indicates a cold anode, thermogalvanic density values were very close to zero after the second hour of coupling, appearing many negative peaks in the thermogalvanic current density signal (Figure 9). These negative peaks imply continuous polarity inversions in the pair, so the hot electrode acted as the anode in several times during the test. 
For the $992 \mathrm{~g} / \mathrm{l} \mathrm{LiBr}$ solution, the hot electrode was the anode of the thermogalvanic pair for the test performed at $25^{\circ} \mathrm{C}-25^{\circ} \mathrm{C}$ and $25^{\circ} \mathrm{C}-50^{\circ} \mathrm{C}$. For the temperature gradients of $25^{\circ} \mathrm{C}-75^{\circ} \mathrm{C}$ and $25^{\circ} \mathrm{C}-100^{\circ} \mathrm{C}$, the cold electrode was initially the anode of the pair, becoming the cathode after a polarity reversal took place (Figure 3c). Figure 8 shows the Nyquist and Bode plots for the pair cold Alloy 31 - hot Alloy 31 in the $992 \mathrm{~g} / \mathrm{L} \mathrm{LiBr}$ solution before and after the thermogalvanic coupling.

In general, it is observed in Figure 8 that the amplitude of the Nyquist plot was higher after the 6 hours of thermogalvanic coupling. The value of the phase angle at low frequencies was higher, as well. These observations suggest an improvement in the protective properties of the passive film formed on its surface with time [72-74].

For the tests performed at $25^{\circ} \mathrm{C}-25^{\circ} \mathrm{C}$ and $25^{\circ} \mathrm{C}-50^{\circ} \mathrm{C}$, the passive film formed on the anode surface (hot electrode) had superior protective properties than the film formed on the cathode surface, as in the rest of $\mathrm{LiBr}$ solutions investigated.

For the temperature gradient of $25^{\circ} \mathrm{C}-75^{\circ} \mathrm{C}$, the improvement of the impedance response after the 6 hours of thermogalvanic coupling is more important for the cold electrode, which was the anode of the pair during the first two hours of the tests. Thus, it can be said that during the first two hours when the cold electrode acted as the anode, the passive film which formed on its surface was more compact and gave the metal a higher degree of protection than the passive film which grew on the hot electrode surface. When the hot electrode became the anode (within the third hour of thermogalvanic coupling), the passive film formed on its surface became more protective than before the coupling but, because of the high temperature $\left(75^{\circ} \mathrm{C}\right)$, this film had worse properties 
than the film formed on the cold electrode. Accordingly, in spite of being the anode only the first two hour of the thermogalvanic coupling, the passive film formed on the cold electrode surface was more protective than that which formed on the hot electrode for the last four hours. For the test performed at $25^{\circ} \mathrm{C}-100^{\circ} \mathrm{C}$, the increase of the Faradic impedance with immersion time was hardly observed for both electrodes. However, for this temperature gradient, the capacitive response of both electrodes improved in the range of low frequencies, indicating better insulating properties of the passive film at the end of the thermogalvanic coupling.

\section{Equivalent circuit and interpretation}

The superior corrosion resistance of stainless steels, such as Alloy 31, is closely related to the passive film formed on their surface. It is generally accepted that the passive film formed on the surface of stainless steels in neutral to alkaline $\mathrm{pH}$ is composed of two layers [46,75-83]. The compact inner layer, known as barrier layer, is composed principally of chromium oxides and is the major contributor. The porous outer layer is composed principally of iron oxides and hydroxides.

From Figures 6-8 it can be readily observed that in most cases two time constants are apparent in the EIS spectra, i.e., a high- and low-frequency capacitive response (for those spectra where these two time constants are not discerned, it is assumed that they exist but are overlapped). This feature is often considered as the response from an inhomogeneous film, which consists of a compact inner layer and a less compact (porous) outer layer $[69,71,76,84-86]$. Figure 10 shows the equivalent circuit (EC) that has been usually used to interpret EIS spectra of passive films having a two-layer 
structure $[69,71,76,84]$, so this circuit (two hierarchically distributed time constants) has been used to simulate the electrochemical behaviour of the present system Alloy 31/LiBr solutions. An example of the quality of the fitting achieved using the equivalent circuit of Figure 10a is shown in Figure 10b for the tests performed in the $400 \mathrm{~g} / \mathrm{l} \mathrm{LiBr}$ solution at $25^{\circ} \mathrm{C}-75^{\circ} \mathrm{C}$. In this model, $R_{S}$ corresponds to the resistance of the electrolyte, and $R_{1}, \mathrm{CPE}_{1}$ and $R_{2}, \mathrm{CPE}_{2}$ to the resistance and capacitance of the outer porous layer and inner barrier layer, respectively. The sum of $R_{1}+R_{2}$ is defined as the polarisation resistance, $R_{p}$, and is related to the corrosion resistance of the metal.

A constant-phase element (CPE) representing a shift from the ideal capacitor was used instead of the capacitance itself. CPEs are used to model frequency dispersion behaviour corresponding to different physical phenomena such as surface heterogeneity which results from surface roughness, impurities, dislocations, formation of porous layers, etc $[70,72,76,87]$. The impedance of a constant-phase element is defined as:

$$
Q=Z_{C P E}=\left[C(j \omega)^{\alpha}\right]^{-1}
$$

where $\alpha$, defined as a CPE power, in an adjustable parameter that lies between -1 and 1 . For $\alpha=1$ the CPE describes and ideal capacitor, and for $\alpha=0$ the CPE is an ideal resistor. When $\alpha=0.5$ the CPE represents a Warburg impedance with diffusional character and for $0.5<\alpha<1$ the CPE describes a frequency dispersion of time constants due to local heterogeneities in the dielectric material. A pure inductance yields $\alpha=-1$.

Therefore, the theoretical impedance of the EC in Figure 10a can be calculated as: 


$$
Z_{T}=R_{S}+\frac{R_{1}+R_{2}+R_{1} R_{2} C_{2}(j \omega)^{\alpha_{2}}}{1+R_{2} C_{2}(j \omega)^{\alpha_{2}}+R_{1} C_{1}(j \omega)^{\alpha_{1}}+R_{2} C_{1}(j \omega)^{\alpha_{1}}+R_{1} R_{2} C_{1} C_{2}(j \omega)^{\alpha_{1}}(j \omega)^{\alpha_{2}}}
$$

The CPE of each subcircuit (inner and outer) has been converted into a pure capacitance (C) by means of the following equation $[68,88,89]$ :

$$
C=\frac{(Q \cdot R)^{1 / \alpha}}{R}
$$

where $Q=\mathrm{Z}_{\mathrm{CPE}}($ eq. (5)).

The conversion shown in Eq. (7) has been done in order to relate pure capacitance values $(C)$ to the thickness of passive film layers, according to the following equation $[90,91]$

$$
C=\frac{\varepsilon \cdot \varepsilon_{0}}{d}
$$

where $\varepsilon$ denotes the relative dielectric constant of the layer, $\varepsilon_{0}$ is the permittivity of vacuum $\left(8.85 \cdot 10^{-14} \mathrm{~F} \mathrm{~cm}^{-1}\right)$ and $d$ is the layer thickness. A value of 15.6 was assumed for $\varepsilon$, as in literature for austenitic stainless steels [75,92]. This value is reasonable, since the dielectric constants of the bulk oxides formed on stainless steels $\left(\mathrm{Cr}_{2} \mathrm{O}_{3}, \mathrm{FeO}\right.$, $\left.\mathrm{Fe}_{3} \mathrm{O}_{4}, \mathrm{Fe}_{2} \mathrm{O}_{3}\right)$ are about 10-20 [92,93]. It is complicated to obtain an accurate thickness value of the passive film when the dielectric constant is not well established and when the surface roughness vary substantially during oxidation processes $[76,89,93,94]$. Moreover, because of the open porous structure, it is difficult to calculate the thickness of the outer layer from the $C_{1}$ values [71]. Nevertheless, neglecting some variation in 
the surface roughness and the dielectric constant, the capacitive response under different conditions can give an indication of how the passive film thickness changed with the changing system conditions.

The resistance, capacitance and $\alpha$ values of the porous and barrier layers obtained by adjusting the experimental data, as well as the thickness of both porous and barrier layer obtained from eq. (8) and the total passive film thickness, are given in Tables 1-3 for the 400, 700 and $992 \mathrm{~g} / \mathrm{L} \mathrm{LiBr}$ solutions at the different imposed temperature gradients.

According to the proposed model, the passive film consists of two layers: the inner barrier layer, whose resistance values $\left(R_{2}\right)$ were significantly larger than the values associated to the outer porous layer $\left(R_{l}\right)$ (Tables 1-3), which is consistent with the chosen physical model. These results indicate that the protection provided by the passive film was predominantly due to the barrier layer. Other authors have obtained similar results for stainless steel [76]. The value of $R_{l}$ (the resistance of the outer layer) depends strongly on the existence of pores, channels or cracks, into which the electrolyte can penetrate and thus provides a sensitive indication of the appearance of such defects in the passive film. If the outer layer is very porous, the parameter $R_{1}$ may correspond approximately to the resistance of the electrolyte inside pores [76]. However, in the present study, $R_{l}$ values were far higher than $R_{S}$ values for all the $\mathrm{LiBr}$ solutions (on the order of $1-100 \mathrm{k} \Omega \cdot \mathrm{cm}^{2}$, Tables 1-3), which indicates that the outer film, in spite of being more porous than the inner barrier layer (since $R_{1}<R_{2}$ ), did not have a high degree of defects. 
From Tables 1-3 it can be seen that high $R_{p}$ values (on the order of $0.1-1 \mathrm{M} \Omega \mathrm{cm}^{2}$ ) were obtained in all the tests, suggesting a high corrosion resistance in the $\mathrm{LiBr}$ solutions employed, because of the formation and growth of a stable and protective passive film. Furthermore, the high values of the exponent $\alpha_{i}$ reveal that CPEs correspond to a nearly capacitive response, and support the physical validity of the proposed equivalent circuit, showing that a better agreement between theoretical and experimental data was obtained if a CPE was introduced rather than pure capacitance and/or Warburg impedance.

In general, both outer and inner layer exhibited similar capacitance values, except for the test performed in the $992 \mathrm{~g} / \mathrm{l} \mathrm{LiBr}$ solution, where the inner layer exhibited higher capacitance $\left(C_{2}\right)$ than the outer layer $\left(C_{1}\right)$, which means that this inner layer was thinner than the outer one at the highest $\mathrm{LiBr}$ concentration. However, since $R_{2}>R_{1}$, the above results regarding passive layers thickness do not mean worse protective properties of the barrier layer. $C_{2}$ values were high compared to the double-layer capacitance expected for a metal/solution interface $\left(10-50 \mu \mathrm{F} / \mathrm{cm}^{2}\right)[95,96]$, especially in the $992 \mathrm{~g} / \mathrm{l} \mathrm{LiBr}$ solution, and were on the order of those obtained by Pan and Zhang [76,97] for capacities of passive films on stainless steels.

The estimated values of $d_{T}=d_{1}+d_{2}$ show that the layers formed on Alloy 31 were typically on the order of $\mathrm{nm}$ in thickness and within the typical range for passive films formed on stainless steels (1-3 nm) [98]. In some cases, these values were slightly higher than $3 \mathrm{~nm}$. As it has been mentioned above, thickness data are only approximations, since changes in the oxide film composition or morphology, as well as changes in the active area due to oxidation processes can alter the dielectric properties, 
$\varepsilon$, of the film $[76,89,93,94]$. Moreover, when the passive film is very thin, the double layer capacitance may not be negligible [93]. Nevertheless, these values give an important indication of how thermogalvanic coupling altered the passive film thickness on the Alloy 31 electrodes.

For the $400 \mathrm{~g} / \mathrm{l} \mathrm{LiBr}$ solution (Table 1), $R_{l}$ increased for the cold electrode (which was always the anode of the pair), indicating that the outer layer formed on this electrode was less defective after the thermogalvanic coupling, whereas it hardly changed for the hot electrode (cathode). It can be seen that the increase in $R_{l}$ for the anode was more noticeable as temperature increased, since higher temperatures favoured the anodic behaviour of the cold electrode. According to the $C_{l}$ and $d_{l}$ values, it can be said that the outer layer barely grew on both electrodes with time. $R_{2}$ and $R_{p}$ increased with coupling time for both electrodes, especially for the cold one (anode), evidencing an improvement of the protective properties of the inner layer. The inner layer grew significantly for the anode (cold electrode) during the thermogalvanic coupling, while its thickness remained constant for the cathode (hot electrode), as it can be observed from $C_{2}$ and $d_{2}$ values. The increase in $R_{2}$ for the anode could be related to the considerable thickening of the inner layer without a noticeable increase in defect level or porosity, which implies a uniform growth of the passive film.

For the $700 \mathrm{~g} / \mathrm{l} \mathrm{LiBr}$ solution (Table 2), $R_{l}$ hardly varied at the end of the thermogalvanic coupling. In general, the outer layer of both electrodes grew to some extent at any temperature gradient. $R_{2}$ and $R_{p}$ increased with coupling time for both electrodes, especially for the anode, suggesting the development of a more protective 
inner layer and, consequently, a more protective passive film. Nevertheless, in the case of the test carried out at $25^{\circ} \mathrm{C}-50^{\circ} \mathrm{C}$, the raise in $R_{2}$ and $R_{p}$ was somewhat higher for the cathode (hot electrode), so the passive film formed on its surface was slightly more protective than the passive film formed on the anode (cold electrode). As it has been mentioned above, the latter result could be related to thermogalvanic current density values, since they were very low and continuous polarity reversals took place over the 6 hours of test. The inner layer of the anode (cold electrode) grew uniformly with thermogalvanic coupling time, which was more perceptible at the highest temperature gradients $\left(25^{\circ} \mathrm{C}-75^{\circ} \mathrm{C}\right.$ and $\left.25^{\circ} \mathrm{C}-100^{\circ} \mathrm{C}\right)$, whereas the $C_{2}$ value for the cathode (hot electrode) hardly changed.

For the $992 \mathrm{~g} / \mathrm{l} \mathrm{LiBr}$ solution (Table 3), at $25^{\circ} \mathrm{C}-25^{\circ} \mathrm{C}$ and $25^{\circ} \mathrm{C}-50^{\circ} \mathrm{C}$, the hot electrode behaved as the anode of the pair, which was reflected in higher values of $R_{2}$ and $R_{p}$, although neither the outer nor the inner layer grew with coupling time, suggesting an improvement in the passive film insulating properties and protectiveness without becoming thicker. The properties of the outer layer barely changed for both electrodes at these imposed temperature gradients. For the tests performed at $25^{\circ} \mathrm{C}-75^{\circ} \mathrm{C}$ and $25^{\circ} \mathrm{C}$ $100^{\circ} \mathrm{C}$ there was a polarity reversal so both electrodes were the anode of the pair at some point in the tests. Thus, the impedance response of both cold and hot electrodes was similar in general terms, since the thickness of the passive film formed on both electrodes barely changed and $R_{2}$ and $R_{p}$ values increased significantly with coupling time. However, because of temperature (the hot electrode was submitted to $75^{\circ} \mathrm{C}$ and $100^{\circ} \mathrm{C}$ ), the total corrosion resistance of the cold electrode was better at the end of the tests, as the higher values of $R_{2}$ and $R_{p}$ denote. 


\section{Conclusions}

Thermogalvanic corrosion generated between the pair cold Alloy 31 - hot Alloy 31 in the studied $\mathrm{LiBr}$ solutions was not severe, since thermogalvanic current densities were rather small. However, the thermogalvanic coupling negatively affects the corrosion resistance of the cold anode. Furthermore, thermogalvanic corrosion will remain as long as temperature gradient exist, representing a dormant situation that can accelerate corrosion if the environment changes.

Seebeck coefficient for the thermogalvanic pair cold Alloy 31 - hot Alloy 31 was found not to be dependant on $\mathrm{LiBr}$ concentration within the concentration range investigated. The positive values of this Seebeck coefficient indicate that the cold electrode of the cell was the anode of the thermogalvanic pair, validating the preceding results.

Alloy 31 exhibited a passive behaviour in the three $\mathrm{LiBr}$ solutions and in the temperature range under study, according with the EIS diagrams, whose shape was characterized by very high impedance values with a highly capacitive behaviour, suggesting that a stable passive film formed on the electrodes surface.

The EIS results indicated that the passive film formed on Alloy 31 in the studied LiBr solutions is composed of a bi-layered oxide consisting of an inner barrier layer an outer porous layer. The resistance of the outer layer $\left(R_{l}\right)$ depends strongly on its defective structure; thus, since $R_{l}$ was far higher than the resistance of the $\mathrm{LiBr}$ electrolytes $\left(R_{S}\right)$, it indicates that the outer porous layer did not have a high degree of defects. 
Nevertheless, it was the inner barrier layer that provided more protective properties to the passive film, since its impedance was higher than that of the outer layer.

The protective properties of the outer layer did not experienced important changes at any temperature gradient, except for the tests performed in the $400 \mathrm{~g} / \mathrm{l} \mathrm{LiBr}$ solution, where the insulating properties and protectiveness of this outer layer improved for the anode of the pair (higher $\mathrm{R}_{1}$ values).

The resistance of the inner layer increased with coupling time for both electrodes, especially for the anode. For the anode in 400 and $700 \mathrm{~g} / 1 \mathrm{LiBr}$ solutions, this raise in $R_{2}$ was accompanied by a uniform thickening of the inner barrier layer. For the anode in the $992 \mathrm{~g} / \mathrm{l} \mathrm{LiBr}$ solution, the inner layer did not grow with coupling time, suggesting an improvement in the passive film insulating properties without becoming thicker. The thickness of the inner layer remained constant for the cathode of the thermogalvanic pair. These results evidence better protective properties of the passive film formed on the anode surface after the thermogalvanic coupling. Thus, the polarity of the electrodes during the thermogalvanic coupling had influence on the passive film properties.

\section{ACKNOWLEDGEMENTS}

We wish express our gratitude to the Ministerio de Ciencia e Innovación (Project CTQ2009-07518), for the economical support of this research, to Thyssen Krupp for supplying the materials, and to Dr. M. Asunción Jaime for her translation assistance. 


\section{REFERENCES}

[1] R.D. Misra, P.K. Sahoo, A. Gupta, Thermoeconomic evaluation and optimization of a double-effect $\mathrm{H} 2 \mathrm{O} / \mathrm{LiBr}$ vapour-absorption refrigeration system, Int. J. Refrig. 28 (2005) 331-343.

[2] S. Aphornratana, T. Sriveerakul, Experimental studies of a single-effect absorption refrigerator using aqueous lithium-bromide: effect of operating condition to system performance, Exp. Therm. Fluid. Sci. 32 (2007) 658-669.

[3] S. Wu, I.W. Eames, Innovations in vapour-absorption cycles, Appl. Energ. 66 (2000) 251-266.

[4] M. Donate, L. Rodriguez, A. De Lucas, J. F. Rodríguez, Thermodynamic evaluation of new absorbent mixtures of lithium bromide and organic salts for absorption refrigeration machines, Int. J. Refrig. 29 (2006) 30-35.

[5] J. S. Kim, F. Ziegler, H. Lee, Simulation of the compressor-assisted triple-effect $\mathrm{H}_{2} \mathrm{O} / \mathrm{LiBr}$ absorption cooling cycles, Appl. Therm. Eng. 22 (2002) 295-308.

[6] P. Srikhirin, S. Aphornratana, S. Chungpaibulpatana, A review of absorption refrigeration technologies, Renew. Sust. Energ. Rev. 5 (2001) 343-372.

[7] A. Igual-Muñoz, J. García-Antón, J. L. Guiñón, V. Pérez-Herranz, Corrosion Behavior and Galvanic Coupling of Stainless Steels, Titanium, and Alloy 33 in Lithium Bromide Solutions, Corrosion 59 (2003) 606-615.

[8] J. L. Guiñón, J. García-Antón, V. Pérez-Herranz, G. Lacoste, Corrosion of Carbon Steels, Stainless Steels, and Titanium in Aqueous Lithium Bromide Solution Corrosion, 50 (1994) 240-248. 
[9] E. A. Abd El Meguid, N. K. Awad, Electrochemical pitting corrosion behaviour of $\alpha$-brass in LiBr containing solutions, Corros. Sci. 51 (2009) 1134-1139.

[10] R.M. Fernández-Domene, E. Blasco-Tamarit, D. M. García-García, J. GarcíaAntón, Repassivation of the damage generated by cavitation on UNS N08031 in a LiBr solution by means of electrochemical techniques and Confocal Laser Scanning Microscopy, Corros. Sci. 52 (2010) 3453-3464.

[11] E. Blasco Tamarit, A. Igual Muñoz, J. García Antón, D. García García, Corrosion behaviour and galvanic coupling of titanium and welded titanium in $\mathrm{LiBr}$ solutions, Corros. Sci. 49 (2007) 1000-1026.

[12] D. Itzhak, O. Elias, Behavior of Type 304 and Type 316 Austenitic Stainless Steels in 55\% Lithium Bromide Heavy Brine Environments, Corrosion 50 (1994) 131137.

[13] A. Igual-Muñoz, J. García-Antón, J.L. Guiñón, V. Pérez-Herranz, Effects of solution temperature on localized corrosion of high nickel content stainless steels and nickel in chromated LiBr solution, Corr. Sci. 48 (2006) 3349-3374.

[14] G.A. Florides, S.A. Kalogirou, S.A. Tassou, L.C. Wrobel, Design and construction of a LiBr-water absorption machine, Energ. Convers. Manage. 44 (2003) 24832508 .

[15] H.H. Uhlig, O.F. Noss, Jr., Potentials Set Up by Thermal Gradients in Iron Immersed in $\mathrm{NaCl}$ Solutions, Corrosion 6 (1950) 140-143.

[16] V.V. Gerasimov, I.L. Rozenfeld, Thermogalvanic corrosion, Izv. Akad. Nauk SSSR (otd khim. nauk) (1957) 29-31. 
[17] L.B. Kriksunov, Thermogalvanic Effects in Corrosion in Supercritical Water, Corrosion 98, NACE, Houston, TX, 1998, paper no. 418.

[18] N.E. Berry, Thermogalvanic Corrosion, Corrosion 2 (1946) 261-267.

[19] R.M. Buffington, Thermogalvanic Corrosion II, Corrosion 3 (1947) 613-631.

[20] V. Ashworth, P.J. Boden, The thermogalvanic corrosion of mild steel in alkaline solution--I. Actively dissolving electrodes, Corros. Sci. 14 (1974) 183-197.

[21] V. Ashworth, P.J. Boden, The thermogalvanic corrosion of mild steel in alkaline solution--II. Passivated electrodes under conditions of film breakdown, Corros. Sci. 14 (1974) 199-208.

[22] V. Ashworth, P.J. Boden, The thermogalvanic corrosion of mild steel in alkaline solution--III. The factors controlling etching, passivation and pitting, Corros. Sci. 14 (1974) 209-224.

[23] E.C. Pitzer, Thermogalvanic Potentials and Currents at Aluminum Surfaces in Industrial Water, J. Electrochem. Soc. 104 (1957) 70-74.

[24] J.R. Myers, A. Cohen, Conditions Contributing to Underground Copper Corrosion, J. AWWA 76 (1984) 68-71.

[25] G. E. C. Bell, M. J. Schiff, D. F. Wilson, Field Observations and Laboratory Investigations of Thermogalvanic Corrosion of Copper Tubing, Corrosion 97, Paper No. 568. 1997. Houston, TX, NACE International.

[26] J.C. Rushing, M. Edwards, The role of temperature gradients in residential copper pipe corrosion, Corros. Sci. 46 (2004) 1883-1894. 
[27] P.J. Boden, Corrosion of $\mathrm{Cu}$ and $\mathrm{Cu}$-base alloys under conditions of boiling heat transfer--I. Corrosion of Cu, Corros. Sci. 11 (1971) 353-362.

[28] V.G. Ereneta, New thermogalvanic method determines the conditions which cause dezincification of admiralty brass in field service, Corros. Sci. 19 (1979) 507-520.

[29] J. Abellà, I. Balachov, D.D. Macdonald, P.J. Millet, Transport processes in steam generator crevices: III. Experimental results, Corros. Sci. 44 (2002) 191-205.

[30] G. Saji, Degradation of aged plants by corrosion: "Long cell action" in unresolved corrosion issues, Nucl. Eng. Des. 239 (2009) 1591-1613.

[31] J. W. Tester, Evaluation of Thermogalvanic Cells for the Conversion of Heat to Electricity, MIT Energy Lab, Technical Report MIT-EL, 92-007 (1992).

[32] R.P. Rastogi, Introduction to Non-equilibrium Physical Chemistry: Towards Complexity and Non-linear Science, 1st ed., Elsevier, Amsterdam, 2008, Ch. 5.

[33] R. Hu, B. A. Cola, N. Haram, J. N. Barisci, S. Lee, S. Stoughton, G. Wallace, C. Too, M. Thomas, A. Gestos, M. E. Cruz, J. P. Ferraris, A. A. Zakhidov and R. H. Baughman, Harvesting Waste Thermal Energy Using a Carbon-Nanotube-Based Thermo-Electrochemical Cell, Nano Lett. 10 (2010) 838-846.

[34] J. C. Verhoef, Electrochemical behaviour of iodide at a rotating platinum disk electrode in methanol, Electrochim. Acta 23 (1978) 433-438.

[35] V.S. Bagotsky, Fundamentals of Electrochemistry, 2nd ed., John Wiley \& Sons, Hoboken, NJ, 2006, Ch. 5. 
[36] B.E. Conway, D.P. Wilkinson, Non-isothermal cell potentials and evaluation of entropies of ions and of activation for single electrode processes in non-aqueous media, Electrochim. Acta 38 (1993) 997-1013.

[37] R.M. Carranza, J.R. Galvele, Repassivation kinetics in stress corrosion cracking--I. Type AISI 304 stainless steel in chloride solutions, Corros. Sci. 28 (1988) 233-249.

[38] G. T. Burstein, P. I. Marshall, Growth of passivating films on scratched 304L stainless steel in alkaline solution, Corros. Sci. 23 (1983) 125-137.

[39] E. Blasco-Tamarit, A. Igual-Muñoz, J. García-Antón, D. García-García, Comparison between open circuit and imposed potential measurements to evaluate the effect of temperature on galvanic corrosion of the pair alloy 31-welded alloy 31 in LiBr solutions, Corros. Sci. 50 (2008) 3590-3598.

[40] D.S. Dunn, G.A. Cragnolino, N. Sridhar, Effect of Galvanic Coupling Between Overpack Materials of High-Level Nuclear Waste Containers, Corrosion 56 (2000) 598-610.

[41] E. Blasco-Tamarit, A. Igual-Muñoz, J. García-Antón, Effect of temperature on the galvanic corrosion of a high alloyed austenitic stainless steel in its welded and non-welded condition in LiBr solutions, Corros. Sci. 49 (2007) 4472-4490.

[42] A. Legat, V. Doleček, Corrosion Monitoring System Based on Measurement and Analysis of Electrochemical Noise, Corrosion 51 (1995) 295-300.

[43] F. Mansfeld, Z. Sun, Technical Note: Localization Index Obtained from Electrochemical Noise Analysis, Corrosion 55 (1999) 915-918. 
[44] E. Blasco-Tamarit, A. Igual-Muñoz, J. García-Antón, D. García-García, Effect of temperature on the corrosion resistance and pitting behaviour of Alloy 31 in $\mathrm{LiBr}$ solutions, Corros. Sci. 50 (2008) 1848-1857.

[45] E. Blasco-Tamarit, D.M. García-García, J. García-Antón, Imposed potential measurements to evaluate the pitting corrosion resistance and the galvanic behaviour of a highly alloyed austenitic stainless steel and its weldment in a $\mathrm{LiBr}$ solution at temperatures up to $150^{\circ} \mathrm{C}$, Corros. Sci. 53 (2011) 784-795.

[46] Z.F. Wang, C.L. Briant, K.S. Kumar, Electrochemical, Galvanic, and Mechanical Responses of Grade 2 Titanium in 6\% Sodium Chloride Solution, Corrosion 55 (1999) 128-138.

[47] E.A. Abd El Meguid, A.A. Abd El Latif, Critical pitting temperature for Type 254 SMO stainless steel in chloride solutions, Corros. Sci. 49 (2007) 263-275.

[48] R. Leiva-García, M.J. Muñoz-Portero, J. García-Antón, Corrosion behaviour of sensitized and unsensitized Alloy 900 (UNS 1.4462) in concentrated aqueous lithium bromide solutions at different temperatures, Corros. Sci. 52 (2010) 950959.

[49] R. Sánchez-Tovar, M.T. Montañés, J. García-Antón, The effect of temperature on the galvanic corrosion of the copper/AISI 304 pair in $\mathrm{LiBr}$ solutions under hydrodynamic conditions, Corros. Sci. 52 (2010) 722-733.

[50] A. Neville, T. Hodgkiess, An assessment of the corrosion behaviour of high-grade alloys in seawater at elevated temperature and under a high velocity impinging flow, Corros. Sci. 38 (1996) 927-956. 
[51] C.T. Kwok, H.C. Man, L.K. Leung, Effect of temperature, $\mathrm{pH}$ and sulphide on the cavitation erosion behaviour of super duplex stainless steel, Wear 211 (1997) 8493.

[52] J.J. Park, S.I. Pyun, S.B. Lee, Growth kinetics of passivating oxide film of Inconel alloy 600 in $0.1 \mathrm{M} \mathrm{Na} 2 \mathrm{SO} 4$ solution at $25-300{ }^{\circ} \mathrm{C}$ using the abrading electrode technique and ac impedance spectroscopy, Electrochim. Acta 49 (2004) 281-292.

[53] R.M. Carranza, M.G. Alvarez, The effect of temperature on the passive film properties and pitting behaviour of a Fe-Cr-Ni alloy, Corros. Sci. 38 (1996) 909925.

[54] K.J. Park, S.J. Ahn, H.S. Kwon, Effects of solution temperature on the kinetic nature of passive film on Ni, Electrochim. Acta 56 (2011) 1662-1669.

[55] E. Blasco-Tamarit, A. Igual-Muñoz, J. García-Antón, D.M. García-García, Galvanic corrosion of titanium coupled to welded titanium in $\mathrm{LiBr}$ solutions at different temperatures, Corros. Sci. 51 (2009) 1095-1102.

[56] P.J. Boden in: L.L. Shreir (Ed.), R.A. Jarman (Ed.), G.T. Burstein (Ed.), Corrosion and Corrosion Control, vol. 1, 3rd ed., Butterworth-Heinemann, Oxford, 1994, Ch. 2.1 (pp. 2:25-2:27).

[57] K. Szabó, E. Földesi, Study of the $\mathrm{CuCu}\left(\mathrm{NO}_{3}\right)_{2} \cdot \mathrm{H}_{2} \mathrm{OCu}$ electrochemical thermocouple at low temperatures, J. Electroanal. Chem. 452 (1998) 107-111.

[58] U.B. Holeschovsky, Analysis of flooded flow fuel cells and thermogalvanic generators, Ph.D. Thesis, Massachusetts Institute of Technology (1994). 
[59] H. Levin, C.F. Bonilla, Thermogalvanic Potentials I. The Application of Thermodynamics to Thermogalvanic Data (A Study of the Silver Chloride Electrode from $25^{\circ}$ to $90^{\circ} \mathrm{C}$ ), J. Electrochem. Soc. 98 (1951) 388-394.

[60] S.N. Lvov, D.D. Macdonald, Estimation of the thermal liquid junction potential of an external pressure balanced reference electrode, J. Electroanal. Chem. 403 (1996) 25-30.

[61] D.D. Pollock in: D.M. Rowe (Ed.), CRC Handbook of Thermoelectrics, 1st ed., CRC Press, Boca Ratón, FL, 1995, Ch. 2.

[62] S.O. Kasap, Thermoelectric effects in metals: thermocouples, An e-booklet, 2001, http://materials.usask.ca/samples/Thermoelectric-Seebeck.pdf (22-03-2011).

[63] H.H. Girault, The Water/Oil/Water Thermocouple and the Ionic Seebeck Effect, J. Chem. Soc., Faraday Trans.1 84 (1988) 2147-2154.

[64] J. Newman, Thermoelectric Effects in Electrochemical Systems, Ind. Eng. Chem. Res. 34 (1995) 3208-3216.

[65] D.S. Carr, C.F. Bonilla, Thermogalvanic Potentials II. Nickel in Neutral Sulfate Solution, J. Electrochem. Soc. 99 (1952) 475-482.

[66] R. Schneebaum, B.R. Sundheim, Thermoelectric Properties of the Silver Nitrate+Sodium Nitrate System, Discuss. Faraday. Soc. 32 (1961) 197-202.

[67] D.D. Macdonald, A.C. Scott, P. Wentrcek, Silver-Silver Chloride Thermocells and Thermal Liquid Junction Potentials for Potassium Chloride Solutions at Elevated Temperatures, J. Electrochem. Soc. 126 (1979) 1618-1624. 
[68] C. Valero Vidal, A. Igual Muñoz, Study of the adsorption process of bovine serum albumin on passivated surfaces of CoCrMo biomedical alloy, Electrochim. Acta 55 (2010) 8445-8452.

[69] S. Luiz de Assis, S. Wolynec, I. Costa, Corrosion characterization of titanium alloys by electrochemical techniques, Electrochim. Acta 51 (2006) 1815-1819.

[70] A. Igual-Muñoz, J. García-Antón, J.L. Guiñón, V. Pérez-Herranz, Inhibition effect of chromate on the passivation and pitting corrosion of a duplex stainless steel in LiBr solutions using electrochemical techniques, Corros. Sci. 49 (2007) 3200-3225.

[71] J. Pan, D. Thierry, C. Leygraf, Electrochemical impedance spectroscopy study of the passive oxide film on titanium for implant application, Electrochim. Acta 41 (1996) 1143-1153.

[72] P. Bommersbach, C. Alemany-Dumont, J.P. Millet, B. Normand, Formation and behaviour study of an environment-friendly corrosion inhibitor by electrochemical methods, Electrochim. Acta 51 (2005) 1076-1084.

[73] C.M. Abreu, M.J. Cristóbal, R. Losada, X.R. Nóvoa, G. Pena, M.C. Pérez, Longterm behaviour of AISI 304L passive layer in chloride containing medium, Electrochim. Acta 51 (2006) 1881-1890.

[74] L. Freire, M.J. Carmezim, M.G.S. Ferreira, M.F. Montemor, The passive behaviour of AISI 316 in alkaline media and the effect of pH: A combined electrochemical and analytical study, Electrochim. Acta 55 (2010) 6174-6181.

[75] N. E. Hakiki, S. Boudin, B. Rondot, M. Da Cunha Belo, The electronic structure of passive films formed on stainless steels, Corros. Sci. 37 (1995) 1809-1822. 
[76] J. Pan, C. Leygraf, R. F. A. Jargelius-Pettersson, J. Lindén, Characterization of High-Temperature Oxide Films on Stainless Steels by Electrochemical-Impedance Spectroscopy, Oxid. Met. 50 (1998) 431-455.

[77] M. Da Cunha Belo, N. E. Hakiki, M. G. S. Ferreira, Semiconducting properties of passive films formed on nickel-base alloys type Alloy 600: influence of the alloying elements, Electrochim. Acta 44 (1999) 2473-2481.

[78] M. F. Montemor, M. G. S. Ferreira, N. E. Hakiki, M. Da Cunha Belo, Chemical composition and electronic structure of the oxide films formed on $316 \mathrm{~L}$ stainless steel and nickel based alloys in high temperature aqueous environments, Corros. Sci. 42 (2000) 1635-1650.

[79] M. G. S. Ferreira, N. E. Hakiki, G. Goodlet, S. Faty, A. M. P. Simoes, M. Da Cunha Belo, Influence of the temperature of film formation on the electronic structure of oxide films formed on 304 stainless steel, Electrochim. Acta 46 (2001) 3767-3776.

[80] H. H. Ge, G. D. Zhou, W. Q. Wu, Passivation model of 316 stainless steel in simulated cooling water and the effect of sulfide on the passive film, Appl. Surf. Sci. 211 (2003) 321-334.

[81] G. Rondelli, P. Torricelli, M. Fini, R. Giardino, In vitro corrosion study by EIS of a nickel-free stainless steel for orthopaedic applications, Biomaterials 26 (2005) 739744. 
[82] M. J. Carmezim, A. M. Simoes, M. F. Montemor, M. Da Cunha Belo, Capacitance behaviour of passive films on ferritic and austenitic stainless steel, Corros. Sci. 47 (2005) 581-591.

[83] B. C. Wang, J. H. Zhu, Influence of ultrasonic cavitation on passive film of stainless steel, Ultrason. Sonochem. 15 (2008) 239-243.

[84] F. Mansfeld, M. W. Kendig, Evaluation of Anodized Aluminum Surfaces with Electrochemical Impedance Spectroscopy, J. Electrochem. Soc. 135 (1988) 828833.

[85] K. Jüttner, Electrochemical impedance spectroscopy (EIS) of corrosion processes on inhomogeneous surfaces, Electrochim. Acta 35 (1990) 1501-1508.

[86] S.I. Pyun, S.M. Moon, S.H. Ahn, S.S. Kim, Effects of $\mathrm{Cl}^{-}, \mathrm{NO}_{3-}$ and $\mathrm{SO}_{4-2}$ ions on anodic dissolution of pure aluminum in alkaline solution, Corros. Sci. 41 (1999) 653-667.

[87] M.E. Orazem, B. Tribollet, Electrochemical Impedance Spectroscopy, 1st ed., John Wiley \& Sons, Hoboken, NJ, 2008, Ch. 13.

[88] N.P. Cosman, K. Fatih, S.G. Roscoe, Electrochemical impedance spectroscopy study of the adsorption behaviour of [alpha]-lactalbumin and [beta]-casein at stainless steel, J. Electroanal. Chem. 574 (2005) 261-271.

[89] A. Kocijan, D.K. Merl, M. Jenko, The corrosion behaviour of austenitic and duplex stainless steels in artificial saliva with the addition of fluoride, Corros. Sci. 53 (2011) 776-783. 
[90] D.D. Macdonald, A. Sun, N. Priyantha, P. Jayaweera, An electrochemical impedance study of Alloy-22 in $\mathrm{NaCl}$ brine at elevated temperature: II. Reaction mechanism analysis, J. Electroanal. Chem. 572 (2004) 421-431.

[91] D.D. Macdonald, M.C.H. McKubre in: E. Barsoukov (Ed.), J.R. Macdonald (Ed.), Impedance Spectroscopy: Theory, Experiment, and Applications, 2nd ed., John Wiley \& Sons, Hoboken, NJ, 2005, Ch. 4.

[92] T.L. Sudesh, L. Wijesinghe, D.J. Blackwood, Photocurrent and capacitance investigations into the nature of the passive films on austenitic stainless steels, Corros. Sci. 50 (2008) 23-34.

[93] D. Wallinder, J. Pan, C. Leygraf, A. Delblanc-Bauer, EIS and XPE study of surface modification of 316LVM stainless steel after passivation, Corros. Sci. 41 (1999) 275-289.

[94] Y.X. Qiao, Y.G. Zheng, W. Ke, P.C. Okafor, Electrochemical behaviour of high nitrogen stainless steel in acidic solutions, Corros. Sci. 51 (2009) 979-986.

[95] A. J. Bard, L. R. Faulkner, Electrochemical Methods: Fundamentals and Applications, 2nd ed., John Wiley \& Sons, New York, NY, 2001, Ch. 1.

[96] M.E. Orazem, B. Tribollet, Electrochemical Impedance Spectroscopy, 1st ed., John Wiley \& Sons, Hoboken, NJ, 2008, Ch. 5.

[97] H. Zhang, Y.L. Zhao, Z.D. Jiang, Effects of temperature on the corrosion behavior of $13 \mathrm{Cr}$ martensitic stainless steel during exposure to $\mathrm{CO} 2$ and $\mathrm{Cl}$ - environment, Mater. Lett. 59 (2005) 3370-3374. 
[98] C.-O.A. Olsson, D. Landolt, Passive films on stainless steels--chemistry, structure and growth, Electrochim. Acta 48 (2003) 1093-1104. 


\section{Tables captions}

Table 1.

Equivalent circuit parameters obtained by fitting the experimental results of EIS, for the thermogalvanic pair cold Alloy 31 - hot Alloy 31 in the $400 \mathrm{~g} / \mathrm{l} \mathrm{LiBr}$ solution at different imposed temperature gradients (BTC: before thermogalvanic coupling; ATC: after thermogalvanic coupling).

Table 2.

Equivalent circuit parameters obtained by fitting the experimental results of EIS, for the thermogalvanic pair cold Alloy 31 - hot Alloy 31 in the $700 \mathrm{~g} / \mathrm{l} \mathrm{LiBr}$ solution at different imposed temperature gradients (BTC: before thermogalvanic coupling; ATC: after thermogalvanic coupling).

Table 3.

Equivalent circuit parameters obtained by fitting the experimental results of EIS, for the thermogalvanic pair cold Alloy 31 - hot Alloy 31 in the $992 \mathrm{~g} / \mathrm{l} \mathrm{LiBr}$ solution at different imposed temperature gradients (BTC: before thermogalvanic coupling; ATC: after thermogalvanic coupling). 
Fig. 1.

Electrochemical cell used for thermogalvanic corrosion tests.

Fig. 2.

Thermogalvanic potential and thermogalvanic current density temporal data of the pair cold Alloy 31 hot Alloy 31 for a temperature gradient of $25^{\circ} \mathrm{C}-75^{\circ} \mathrm{C}$ in the (a) $400 \mathrm{~g} / \mathrm{l} \mathrm{LiBr}$, (b) $700 \mathrm{~g} / \mathrm{LiBr}$ and (c) 992 $\mathrm{g} / \mathrm{L} \mathrm{LiBr}$ solutions.

Fig. 3.

Mean values of thermogalvanic current density registered between the pair cold Alloy 31 - hot Alloy 31 during each hour of the test at different imposed temperature gradients in the (a) $400 \mathrm{~g} / \mathrm{l} \mathrm{LiBr}$, (b) $700 \mathrm{~g} / 1$ $\mathrm{LiBr}$ and (c) $992 \mathrm{~g} / \mathrm{l} \mathrm{LiBr}$ solutions.

Fig. 4.

Mean values of thermogalvanic potential registered between the pair cold Alloy 31 - hot Alloy 31 during each hour of the test at different imposed temperature gradients in the (a) $400 \mathrm{~g} / \mathrm{l} \mathrm{LiBr}$, (b) $700 \mathrm{~g} / \mathrm{L} \mathrm{LiBr}$ and (c) $992 \mathrm{~g} / \mathrm{l} \mathrm{LiBr}$ solutions.

Fig. 5.

Thermogalvanic potential $\left(E_{t h}\right)$ vs. temperature gradient $(\Delta \mathrm{T})$ for the three LiBr solutions under study.

Fig. 6.

Nyquist and Bode-phase plots for the pair cold Alloy 31 - hot Alloy 31 at OCP in the $400 \mathrm{~g} / 1 \mathrm{LiBr}$ solution at the temperature gradients of (a) $25^{\circ} \mathrm{C}-25^{\circ} \mathrm{C}$, (b) $25^{\circ} \mathrm{C}-50^{\circ} \mathrm{C}$ and (c) $25^{\circ} \mathrm{C}-75^{\circ} \mathrm{C}$, before and after the thermogalvanic coupling (BTC and ATC, respectively).

Fig. 7.

Nyquist and Bode-phase plots for the pair cold Alloy 31 - hot Alloy 31 at OCP in the $700 \mathrm{~g} / \mathrm{LiBr}$ solution at the temperature gradients of (a) $25^{\circ} \mathrm{C}-25^{\circ} \mathrm{C}$, (b) $25^{\circ} \mathrm{C}-50^{\circ} \mathrm{C}$, (c) $25^{\circ} \mathrm{C}-75^{\circ} \mathrm{C}$ and (d) $25^{\circ} \mathrm{C}-100^{\circ} \mathrm{C}$, before and after the thermogalvanic coupling (BTC and ATC, respectively). 
Fig. 8 .

Nyquist and Bode-phase plots for the pair cold Alloy 31 - hot Alloy 31 at OCP in the $992 \mathrm{~g} / 1 \mathrm{LiBr}$ solution at the temperature gradients of (a) $25^{\circ} \mathrm{C}-25^{\circ} \mathrm{C}$, (b) $25^{\circ} \mathrm{C}-50^{\circ} \mathrm{C}$, (c) $25^{\circ} \mathrm{C}-75^{\circ} \mathrm{C}$ and (d) $25^{\circ} \mathrm{C}-100^{\circ} \mathrm{C}$, before and after the thermogalvanic coupling (BTC and ATC, respectively).

Fig. 9.

Thermogalvanic potential and thermogalvanic current density temporal data of the pair cold Alloy 31 hot Alloy 31 for a temperature gradient of $25^{\circ} \mathrm{C}-50^{\circ} \mathrm{C}$ in the $700 \mathrm{~g} / \mathrm{l} \mathrm{LiBr}$ solution.

Fig. 10.

(a) Representation of the equivalent circuits used for a two-layer model of passive film and proposed for the interpretation of EIS spectra; (b) experimental results and simulated data for the pair cold Alloy 31 hot Alloy 31 at OCP in the $400 \mathrm{~g} / 1 \mathrm{LiBr}$ solution at the temperature gradient of $25^{\circ} \mathrm{C}-75^{\circ} \mathrm{C}$, before and after the thermogalvanic coupling (BTC and ATC, respectively). 


\begin{tabular}{|c|c|c|c|c|c|c|c|c|c|c|c|}
\hline Electrode & $R_{S}\left(\Omega \mathrm{cm}^{2}\right)$ & $R_{l}\left(\mathrm{k} \Omega \mathrm{cm}^{2}\right)$ & $C_{l}\left(\mu \mathrm{F} / \mathrm{cm}^{2}\right)$ & $\alpha_{1}$ & $d_{l}(\mathrm{~nm})$ & $R_{2}\left(\mathrm{k} \Omega \mathrm{cm}^{2}\right)$ & $C_{2}\left(\mu \mathrm{F} / \mathrm{cm}^{2}\right)$ & $\alpha_{2}$ & $d_{2}(\mathrm{~nm})$ & $R_{P}\left(\mathrm{k} \Omega \mathrm{cm}^{2}\right)$ & $d_{T}(\mathrm{~nm})$ \\
\hline \multicolumn{12}{|l|}{$25^{\circ} \mathrm{C}-25^{\circ} \mathrm{C}$} \\
\hline Cold and hot (BTC) & 1.2 & 57.8 & 48.0 & 0.74 & 0.3 & 209 & 19.8 & 0.81 & 0.7 & 266.8 & 1.0 \\
\hline Cold (ATC) & 1.2 & 92.3 & 26.4 & 0.93 & 0.5 & 925 & 4.9 & 0.92 & 2.8 & 1017 & 3.3 \\
\hline Hot (ATC) & 1.5 & 31.7 & 26.4 & 0.95 & 0.5 & 522 & 23.8 & 0.83 & 0.6 & 554 & 1.1 \\
\hline \multicolumn{12}{|l|}{$25^{\circ} \mathrm{C}-50^{\circ} \mathrm{C}$} \\
\hline Cold (BTC) & 1.2 & 57.8 & 48.0 & 0.74 & 0.3 & 209 & 19.8 & 0.81 & 0.7 & 266.8 & 1.0 \\
\hline Hot (BTC) & 0.9 & 17.1 & 29.8 & 0.95 & 0.5 & 146 & 29.8 & 0.80 & 0.5 & 136.1 & 1.0 \\
\hline Cold (ATC) & 1.1 & 179 & 31.9 & 0.91 & 0.4 & 1140 & 3.2 & 0.86 & 4.3 & 1319 & 4.7 \\
\hline Hot (ATC) & 0.9 & 16.8 & 28.9 & 0.93 & 0.5 & 493 & 46.9 & 0.76 & 0.3 & 509.8 & 0.8 \\
\hline \multicolumn{12}{|l|}{$25^{\circ} \mathrm{C}-75^{\circ} \mathrm{C}$} \\
\hline Cold (BTC) & 1.2 & 57.8 & 48.0 & 0.74 & 0.3 & 209 & 19.8 & 0.81 & 0.7 & 266.8 & 1.0 \\
\hline Hot (BTC) & 0.7 & 1.9 & 31.6 & 0.95 & 0.4 & 178 & 72 & 0.84 & 1.9 & 179.9 & 2.3 \\
\hline Cold (ATC) & 1.1 & 922 & 31.5 & 0.90 & 0.4 & 1880 & 1.5 & 0.90 & 9.3 & 2802 & 9.7 \\
\hline Hot (ATC) & 0.7 & 1.7 & 30.7 & 0.90 & 0.4 & 427 & 187 & 0.83 & $>0.1$ & 428.7 & 0.4 \\
\hline
\end{tabular}




\begin{tabular}{|c|c|c|c|c|c|c|c|c|c|c|c|}
\hline Electrode & $R_{S}\left(\Omega \mathrm{cm}^{2}\right)$ & $R_{l}\left(\mathrm{k} \Omega \mathrm{cm}^{2}\right)$ & $C_{l}\left(\mu \mathrm{F} / \mathrm{cm}^{2}\right)$ & $\alpha_{1}$ & $d_{1}(\mathrm{~nm})$ & $R_{2}\left(\mathrm{k} \Omega \mathrm{cm}^{2}\right)$ & $C_{2}\left(\mu \mathrm{F} / \mathrm{cm}^{2}\right)$ & $\alpha_{2}$ & $d_{2}(\mathrm{~nm})$ & $R_{P}\left(\mathrm{k} \Omega \mathrm{cm}^{2}\right)$ & $d_{T}(\mathrm{~nm})$ \\
\hline \multicolumn{12}{|l|}{$25^{\circ} \mathrm{C}-25^{\circ} \mathrm{C}$} \\
\hline Cold and hot (BTC) & 1.2 & 15 & 35.6 & 0.93 & 0.4 & 212 & 50 & 0.76 & 0.3 & 226.9 & 0.7 \\
\hline Cold (ATC) & 1.6 & 13.6 & 22.9 & 0.96 & 0.6 & 1950 & 52.2 & 0.81 & 0.3 & 1963.6 & 0.9 \\
\hline Hot (ATC) & 1.2 & 9.9 & 39.2 & 0.94 & 0.4 & 419 & 70.3 & 0.79 & 0.2 & 428.9 & 0.6 \\
\hline & & & & & & & & & & & \\
\hline \multicolumn{12}{|l|}{$25^{\circ} \mathrm{C}-50^{\circ} \mathrm{C}$} \\
\hline Cold (BTC) & 1.2 & 15 & 35.6 & 0.93 & 0.4 & 212 & 50 & 0.76 & 0.3 & 226.9 & 0.7 \\
\hline Hot (BTC) & 0.9 & 6.9 & 35.0 & 0.92 & 0.4 & 222 & 63.7 & 0.77 & 0.2 & 228.9 & 0.6 \\
\hline Cold (ATC) & 1.1 & 10.4 & 24.2 & 0.95 & 0.6 & 1380 & 117 & 0.68 & 0.1 & 1390.4 & 0.7 \\
\hline Hot (ATC) & 1.0 & 7.0 & 28.3 & 0.92 & 0.5 & 1830 & 69.2 & 0.81 & 0.2 & 1837 & 0.7 \\
\hline \multicolumn{12}{|l|}{$25^{\circ} \mathrm{C}-75^{\circ} \mathrm{C}$} \\
\hline Cold (BTC) & 1.2 & 15 & 35.6 & 0.93 & 0.4 & 212 & 50 & 0.76 & 0.3 & 227 & 0.7 \\
\hline Hot (BTC) & 0.8 & 0.6 & 27.9 & 0.94 & 0.5 & 153 & 49.7 & 0.85 & 0.3 & 153.6 & 0.8 \\
\hline Cold (ATC) & 1.1 & 15.9 & 25.1 & 0.94 & 0.6 & 1390 & 22.3 & 0.83 & 0.6 & 1421.9 & 1.2 \\
\hline Hot (ATC) & 0.8 & 1.4 & 26.1 & 0.92 & 0.5 & 576 & 43.1 & 0.89 & 0.3 & 577.4 & 0.8 \\
\hline \multicolumn{12}{|l|}{$25^{\circ} \mathrm{C}-100^{\circ} \mathrm{C}$} \\
\hline Cold (BTC) & 1.2 & 15 & 35.6 & 0.93 & 0.4 & 212 & 50 & 0.76 & 0.3 & 227 & 0.7 \\
\hline Hot (BTC) & 0.6 & 1.7 & 38.3 & 0.92 & 0.4 & 79.3 & 100 & 0.85 & 0.1 & 81 & 0.5 \\
\hline Cold (ATC) & 1.0 & 4.2 & 20.7 & 0.89 & 0.7 & 3640 & 2.5 & 0.93 & 5.6 & 3644.2 & 6.3 \\
\hline Hot (ATC) & 0.6 & 0.4 & 26.9 & 0.96 & 0.5 & 86.2 & 183 & 0.82 & 0.1 & 86.6 & 0.6 \\
\hline
\end{tabular}




\begin{tabular}{|c|c|c|c|c|c|c|c|c|c|c|c|}
\hline Electrode & $R_{S}\left(\Omega \mathrm{cm}^{2}\right)$ & $R_{l}\left(\mathrm{k} \Omega \mathrm{cm}^{2}\right)$ & $C_{l}\left(\mu \mathrm{F} / \mathrm{cm}^{2}\right)$ & $\alpha_{1}$ & $d_{l}(\mathrm{~nm})$ & $R_{2}\left(\mathrm{k} \Omega \mathrm{cm}^{2}\right)$ & $C_{2}\left(\mu \mathrm{F} / \mathrm{cm}^{2}\right)$ & $\alpha_{2}$ & $d_{2}(\mathrm{~nm})$ & $R_{P}\left(\mathrm{k} \Omega \mathrm{cm}^{2}\right)$ & $d_{T}(\mathrm{~nm})$ \\
\hline \multicolumn{12}{|l|}{$25^{\circ} \mathrm{C}-25^{\circ} \mathrm{C}$} \\
\hline Cold and hot (BTC) & 2.1 & 5.6 & 35.8 & 0.89 & 0.4 & 154 & 407 & 0.71 & $>0.1$ & 159.6 & 0.4 \\
\hline Cold (ATC) & 3.1 & 4.0 & 35.5 & 0.92 & 0.4 & 2900 & 1390 & 0.66 & $>0.1$ & 2904 & 0.4 \\
\hline Hot (ATC) & 2.2 & 9.2 & 32.4 & 0.95 & 0.4 & 796 & 101 & 0.83 & 0.1 & 805.2 & 0.5 \\
\hline \multicolumn{12}{|l|}{$25^{\circ} \mathrm{C}-50^{\circ} \mathrm{C}$} \\
\hline Cold (BTC) & 2.1 & 5.6 & 35.8 & 0.89 & 0.4 & 154 & 407 & 0.71 & $>0.1$ & 159.6 & 0.4 \\
\hline Hot (BTC) & 1.6 & 2.8 & 44.3 & 0.90 & 0.3 & 188 & 198 & 0.78 & $>0.1$ & 190.8 & 0.3 \\
\hline Cold (ATC) & 1.8 & 7.3 & 41.6 & 0.89 & 0.3 & 337 & 613 & 0.75 & $>0.1$ & 344.2 & 0.3 \\
\hline Hot (ATC) & 1.6 & 1.6 & 55.8 & 0.93 & 0.2 & 930 & 146 & 0.85 & $>0.1$ & 931.6 & 0.2 \\
\hline \multicolumn{12}{|l|}{$25^{\circ} \mathrm{C}-75^{\circ} \mathrm{C}$} \\
\hline Cold (BTC) & 2.1 & 5.6 & 35.8 & 0.89 & 0.4 & 154 & 407 & 0.71 & $>0.1$ & 159.6 & 0.4 \\
\hline Hot (BTC) & 0.9 & 6.4 & 34.2 & 0.82 & 0.4 & 147 & 703 & 0.84 & $>0.1$ & 153.4 & 0.4 \\
\hline Cold (ATC) & 2.5 & 5.0 & 31.8 & 0.92 & 0.4 & 6150 & 150 & 0.87 & $>0.1$ & 6155 & 0.4 \\
\hline Hot (ATC) & 0.9 & 1.8 & 25.9 & 0.85 & 0.5 & 1150 & 345 & 0.83 & $>0.1$ & 1151.8 & 0.5 \\
\hline \multirow{2}{*}{\multicolumn{12}{|c|}{$25^{\circ} \mathrm{C}-100^{\circ} \mathrm{C}$}} \\
\hline & & & & & & & & & & & \\
\hline Cold (BTC) & 2.1 & 5.6 & 35.8 & 0.89 & 0.4 & 154 & 407 & 0.71 & $>0.1$ & 159.6 & 0.4 \\
\hline Hot (BTC) & 1.0 & 2.8 & 50.7 & 0.93 & 0.3 & 53.2 & 182 & 0.81 & $>0.1$ & 56 & 0.3 \\
\hline Cold (ATC) & 1.8 & 0.9 & 28.7 & 0.91 & 0.5 & 1630 & 2800 & 0.74 & $>0.1$ & 1630.9 & 0.5 \\
\hline Hot (ATC) & 0.9 & 3.0 & 51.4 & 0.93 & 0.3 & 545 & 207 & 0.83 & $>0.1$ & 548 & 0.3 \\
\hline
\end{tabular}




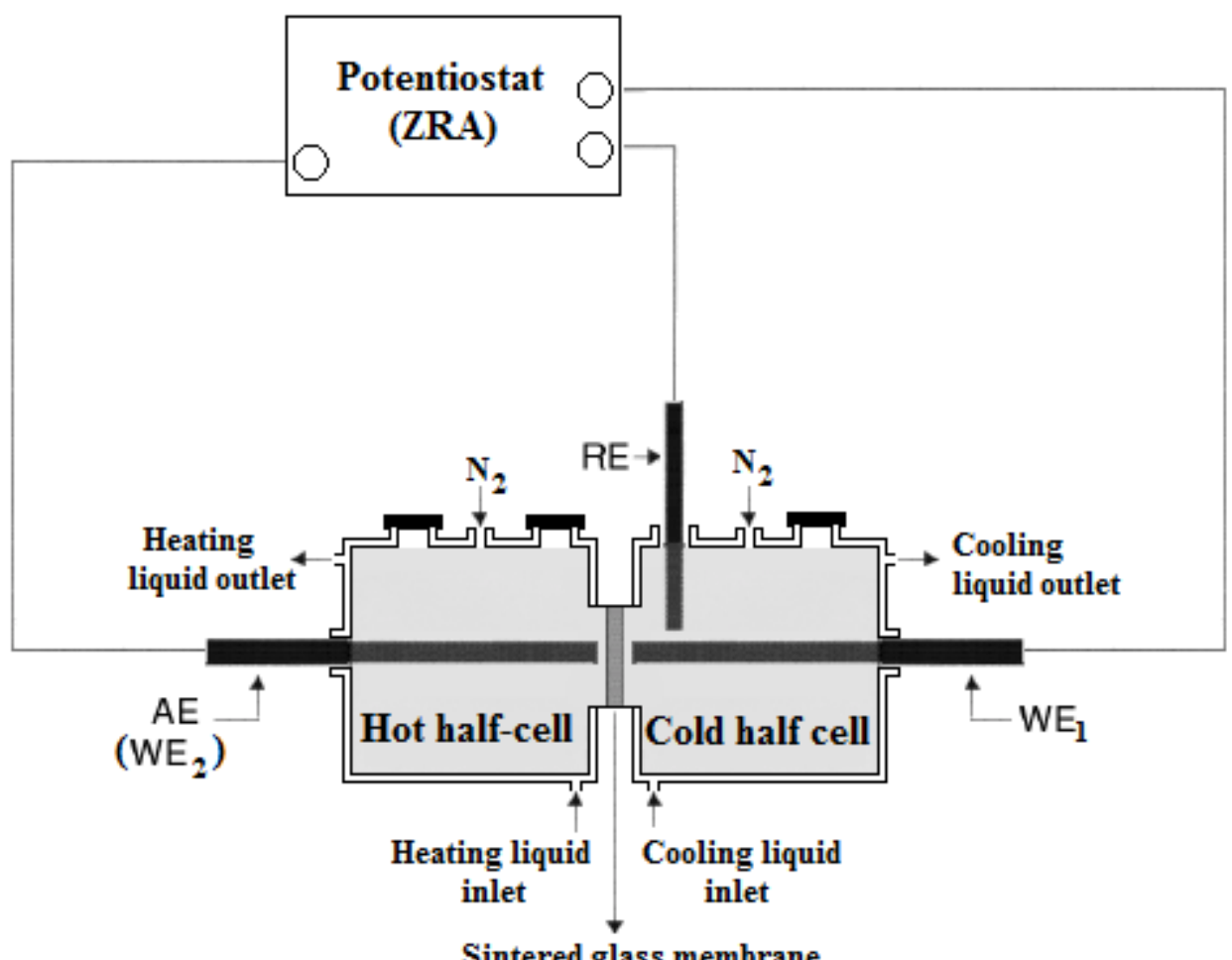

Sintered glass membrane 
Figure 2

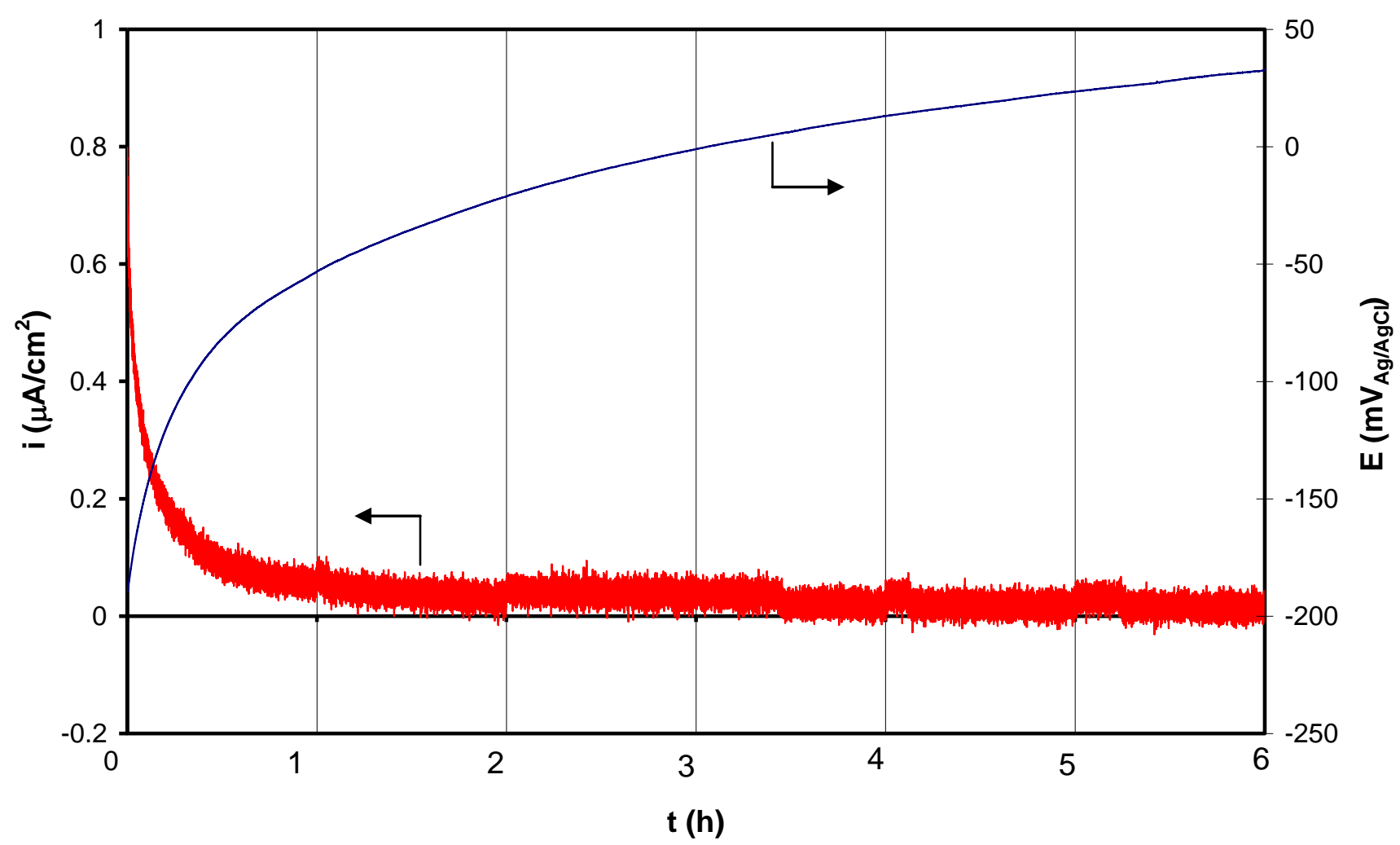

(a)

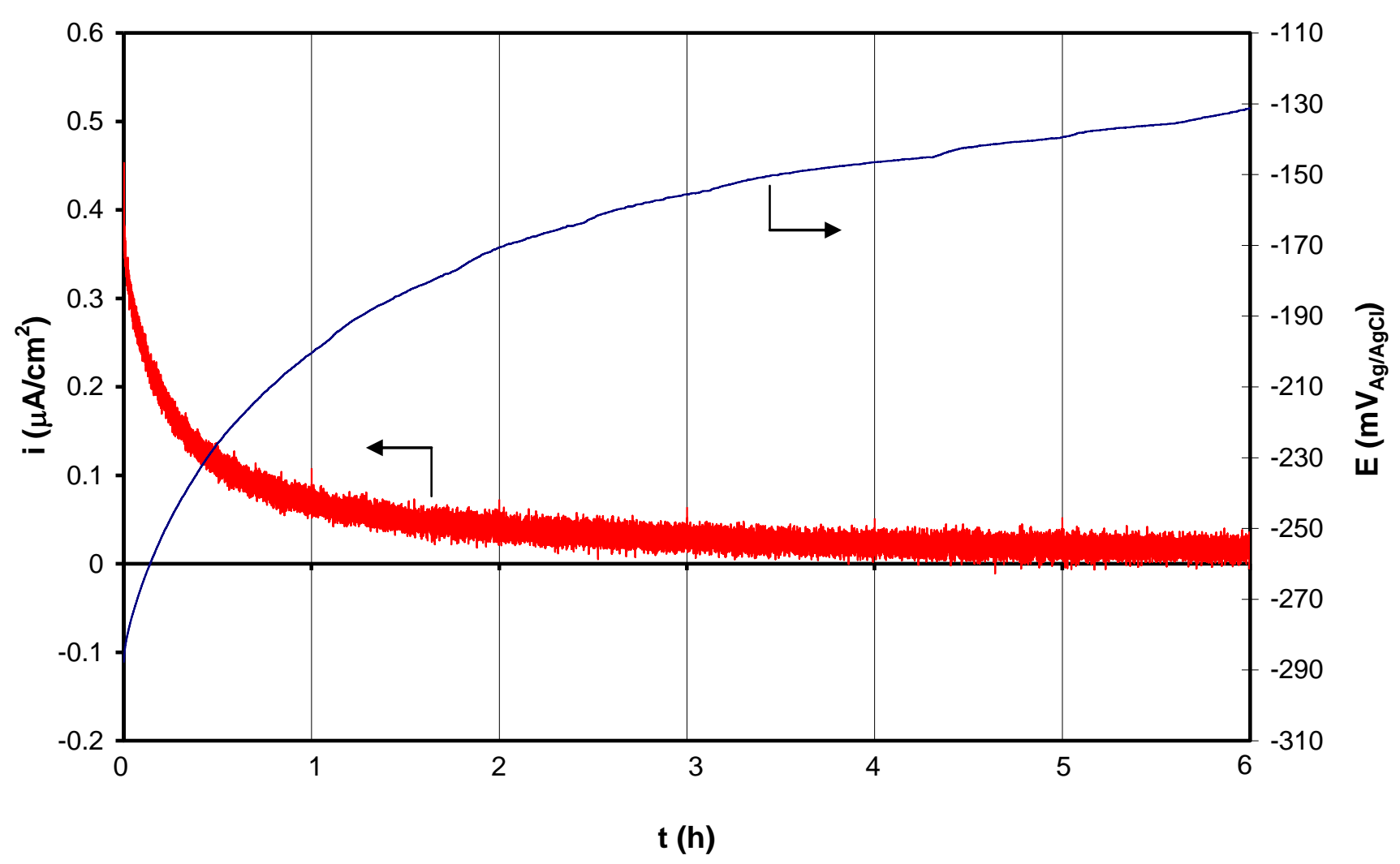

(b) 


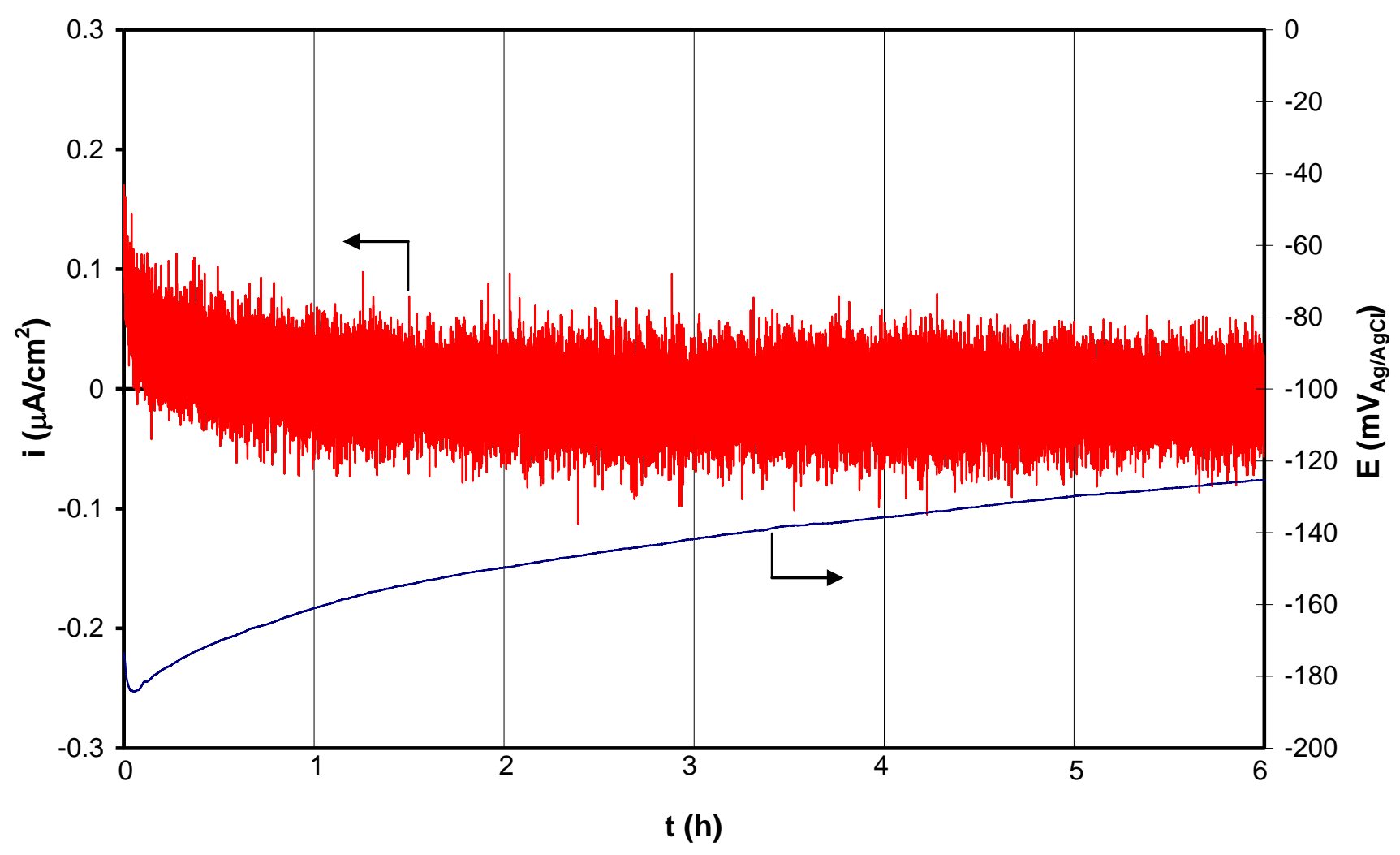

(c) 


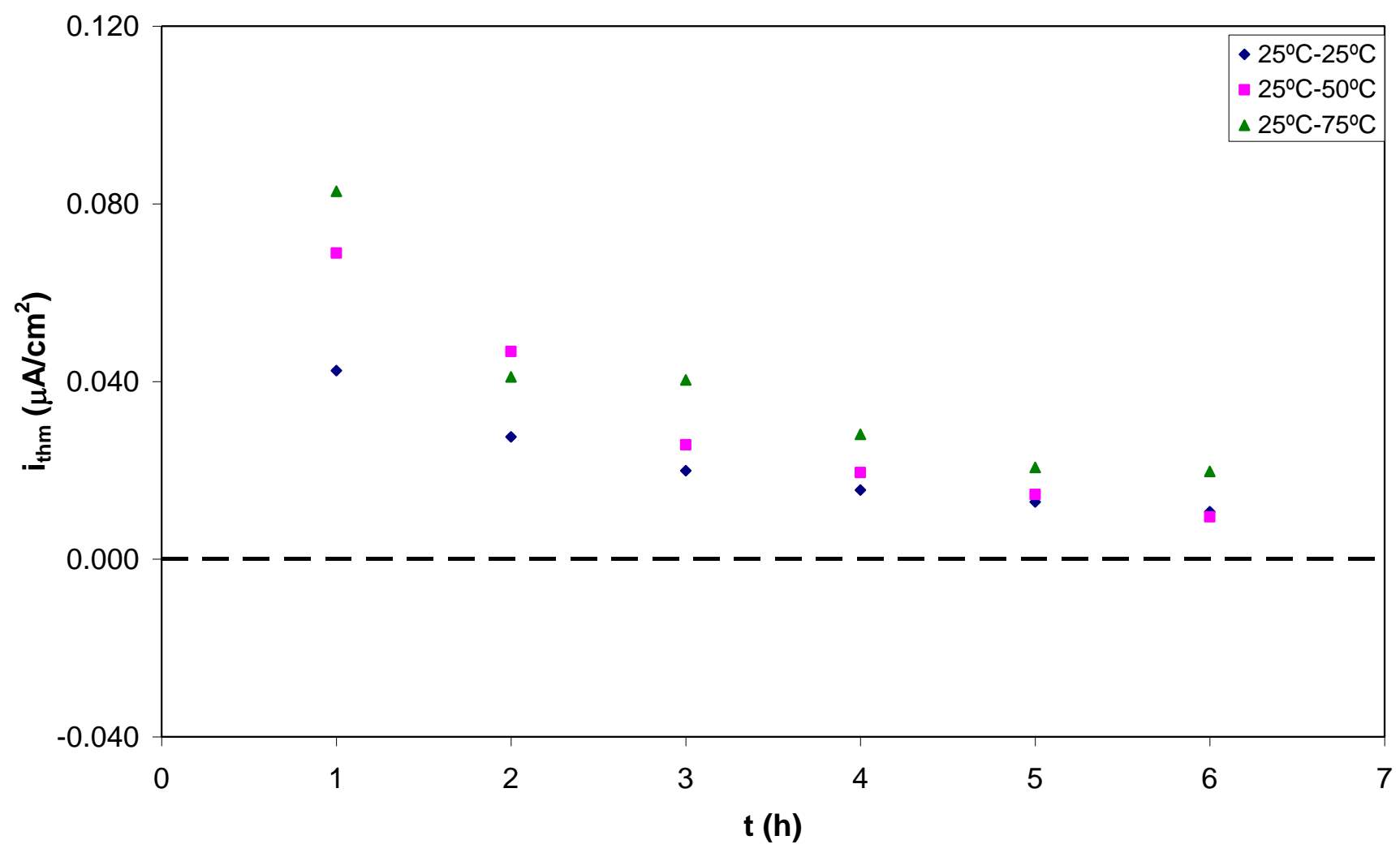

(a)

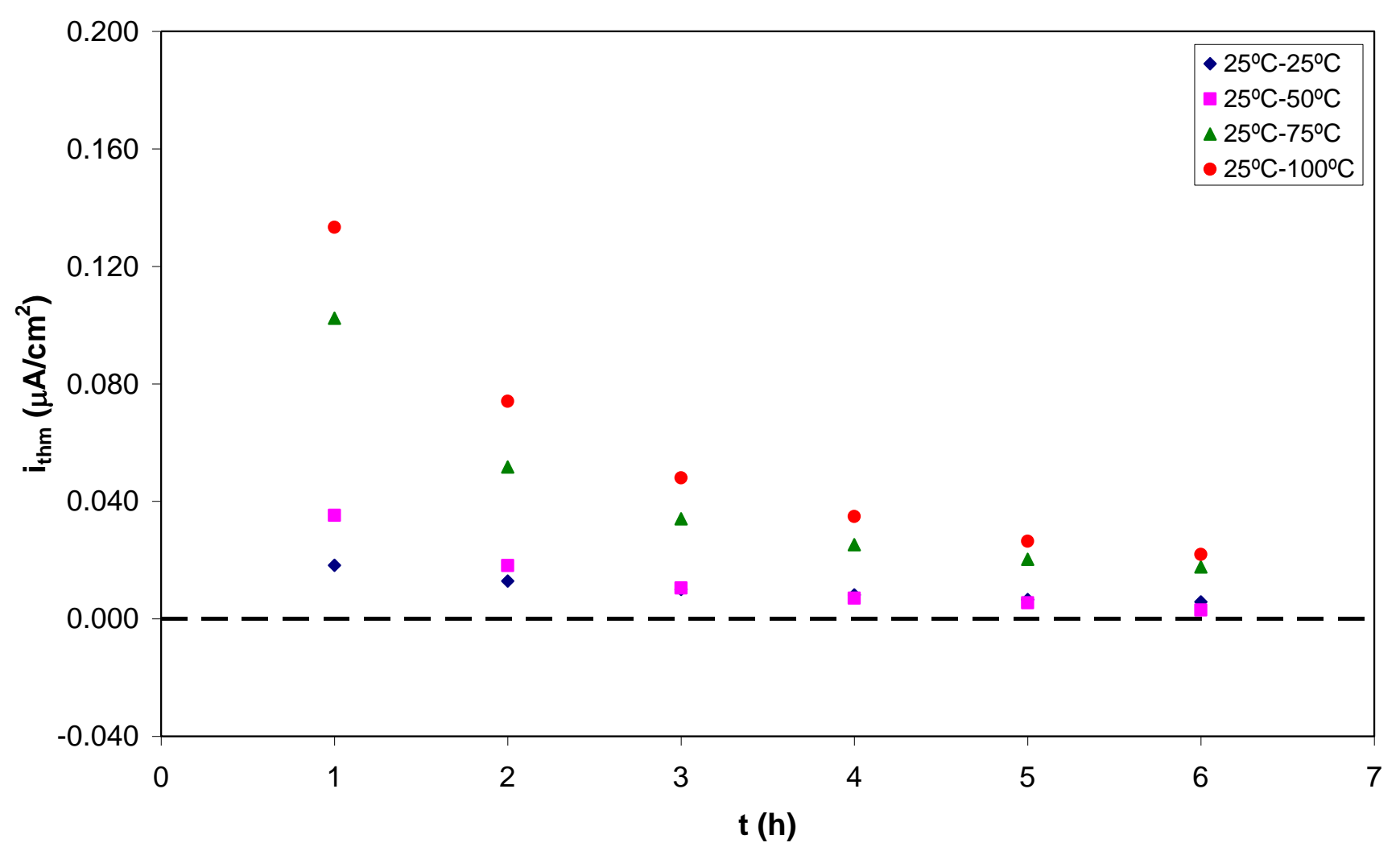

(b) 


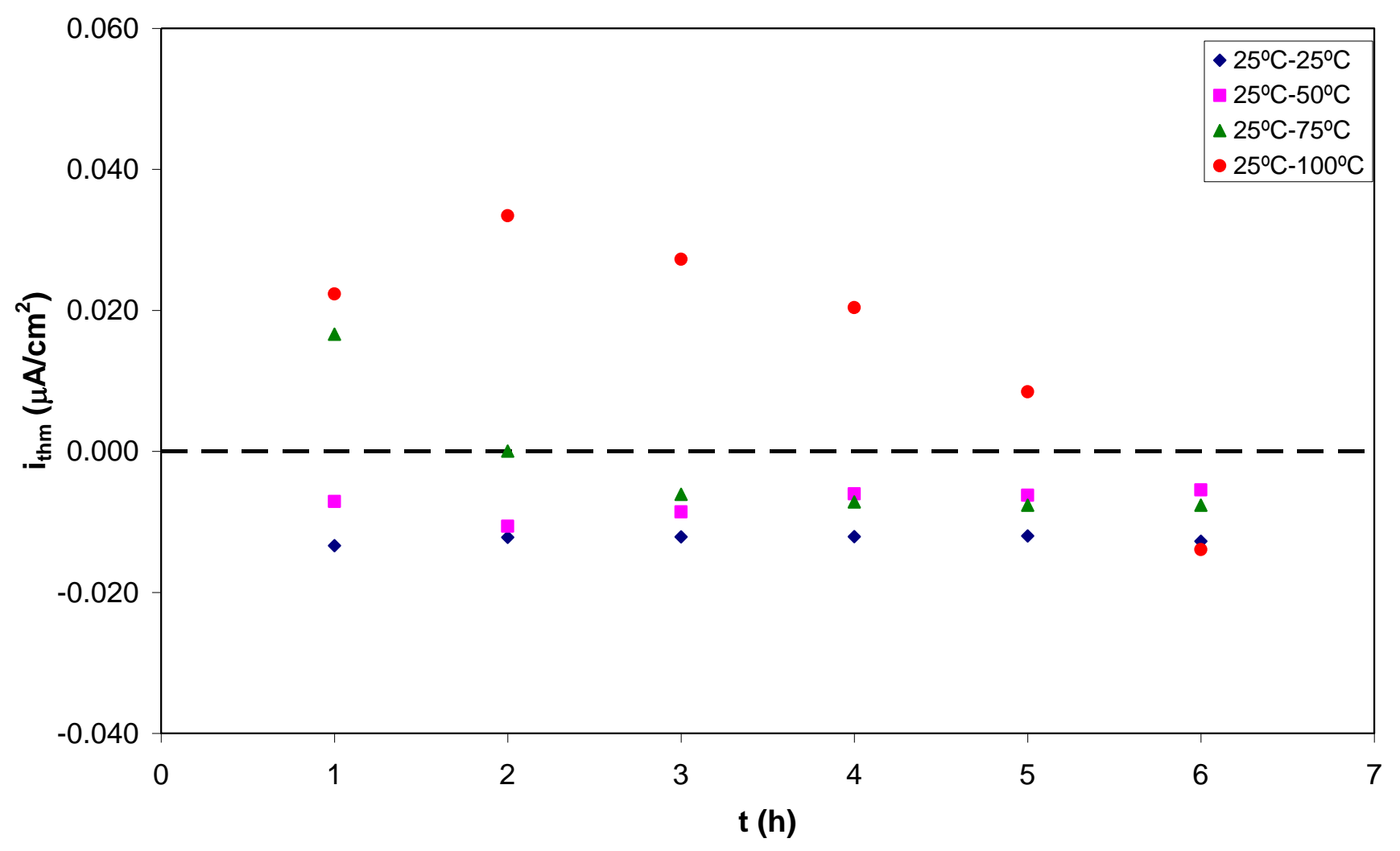

(c) 


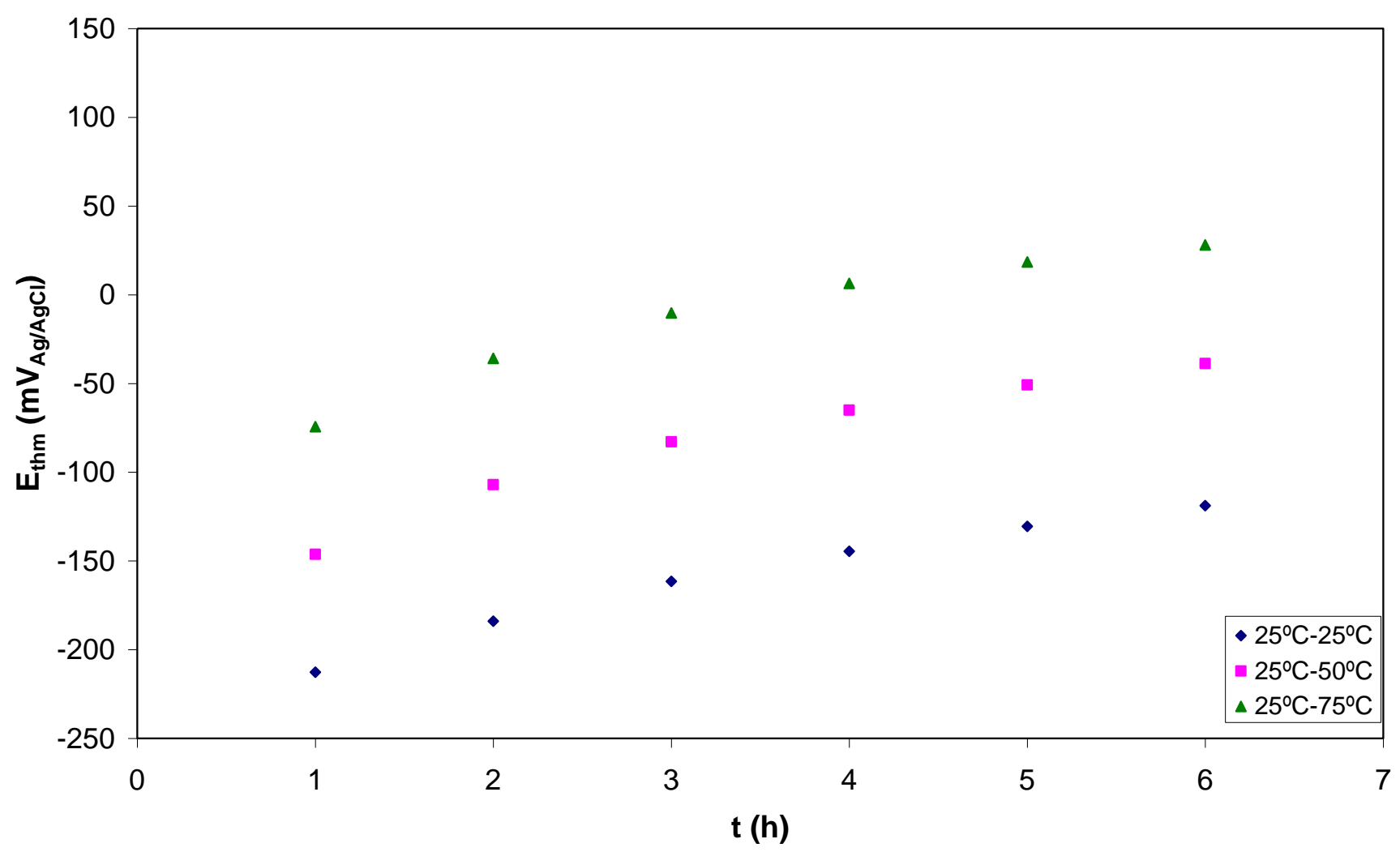

(a)

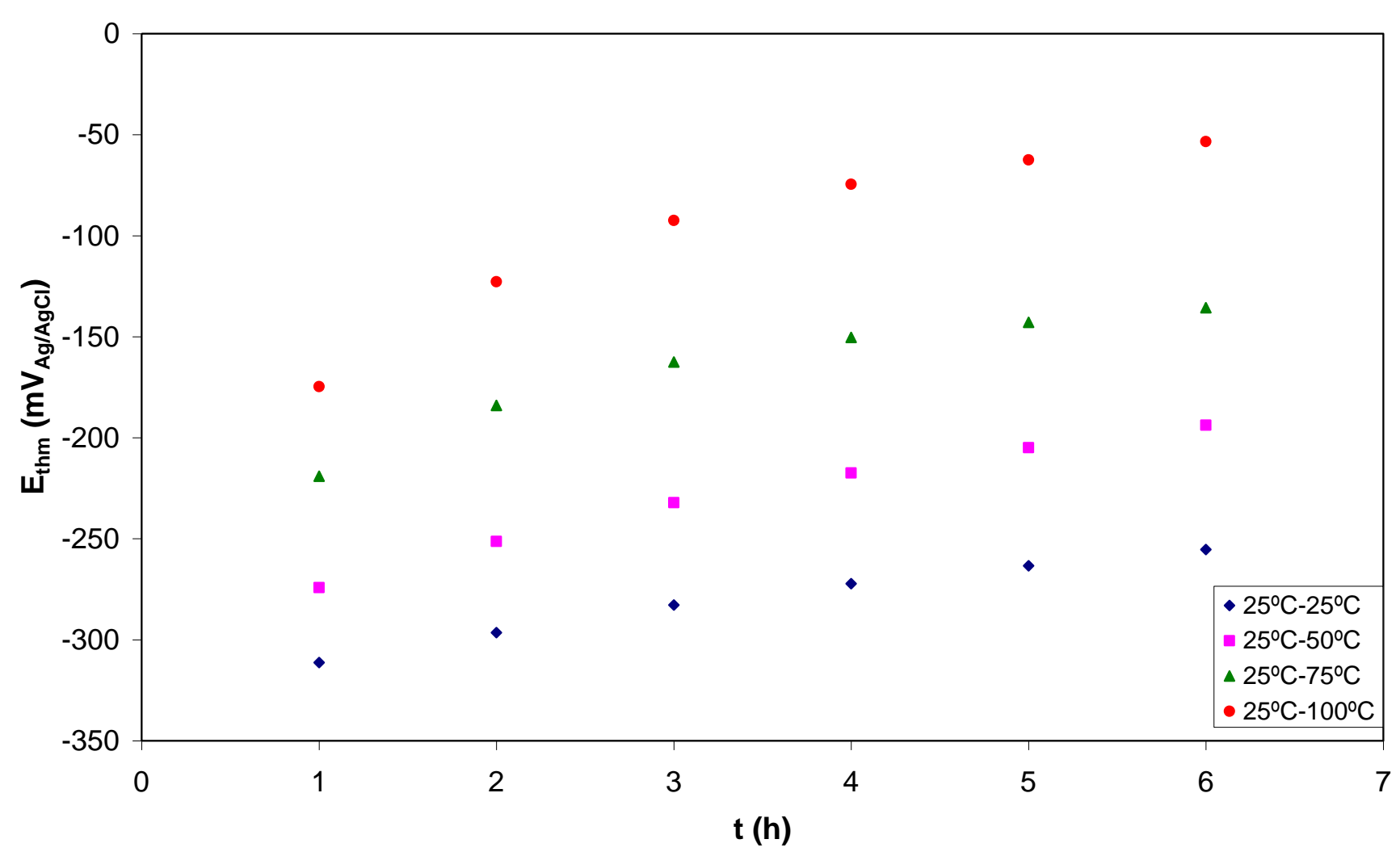

(b) 


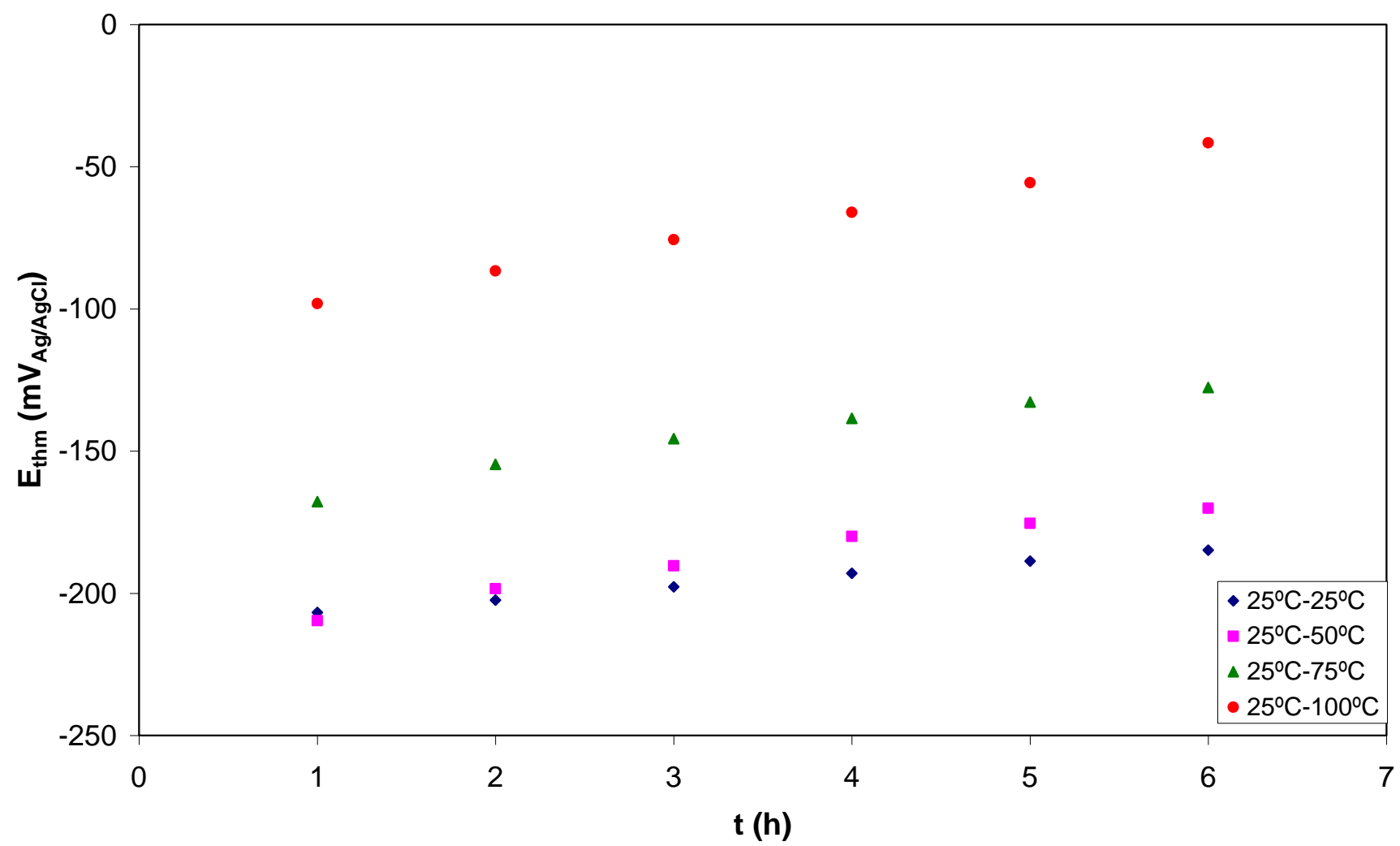

(c) 
Figure 5

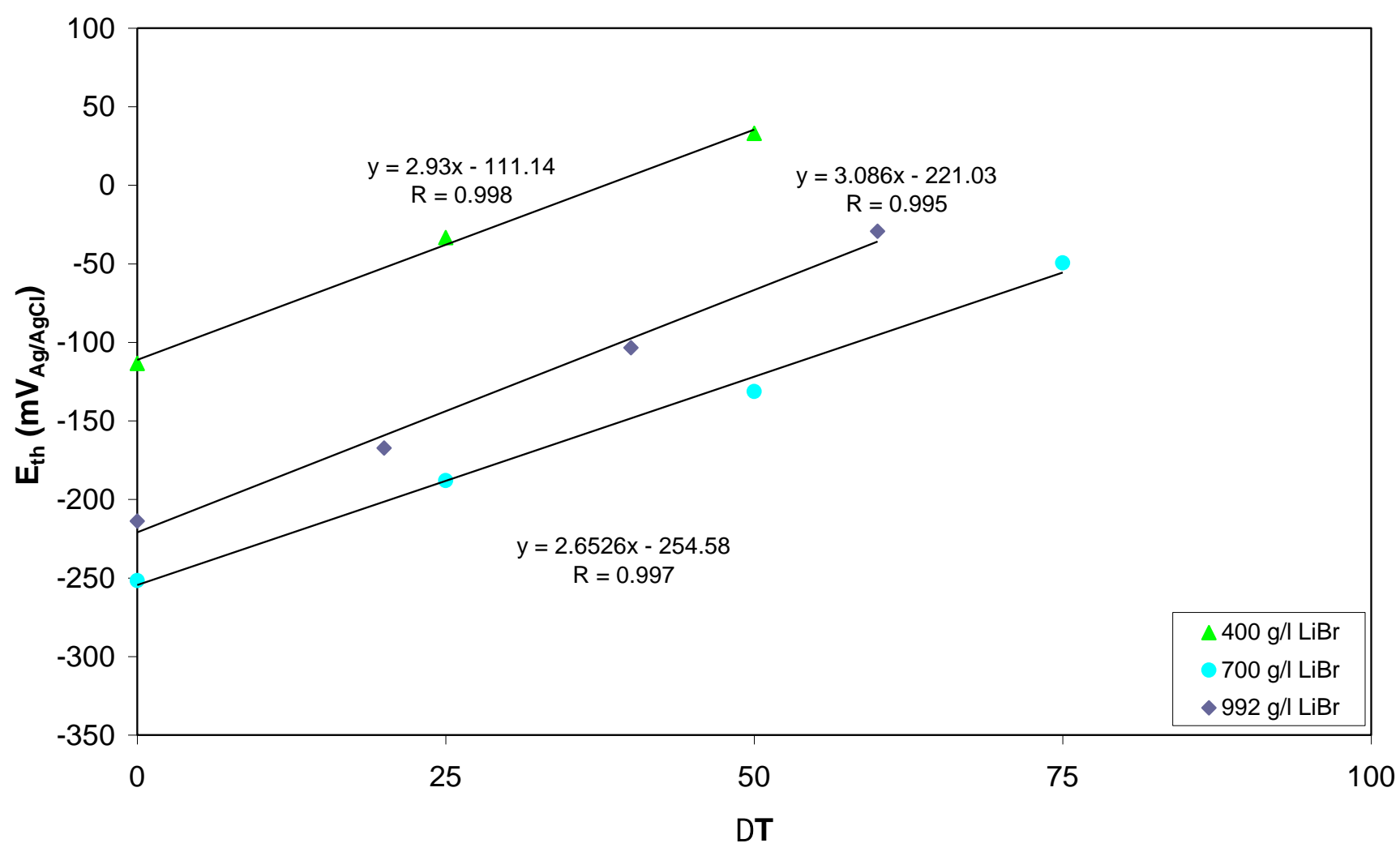



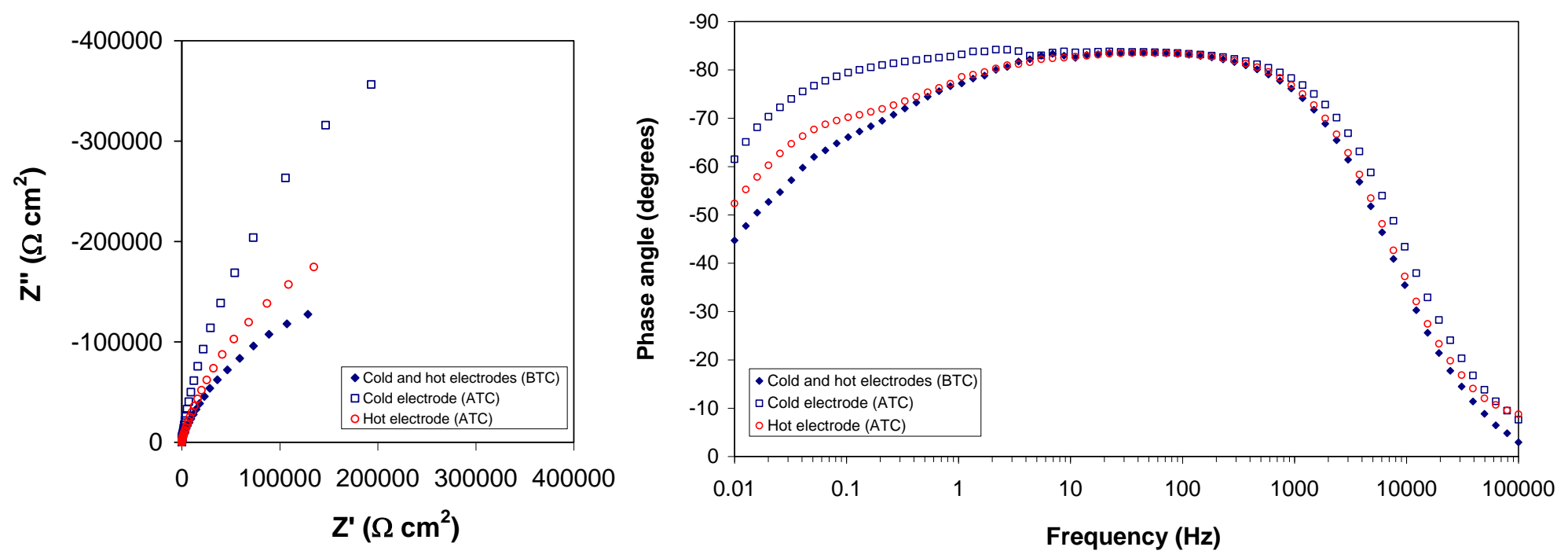

(a)
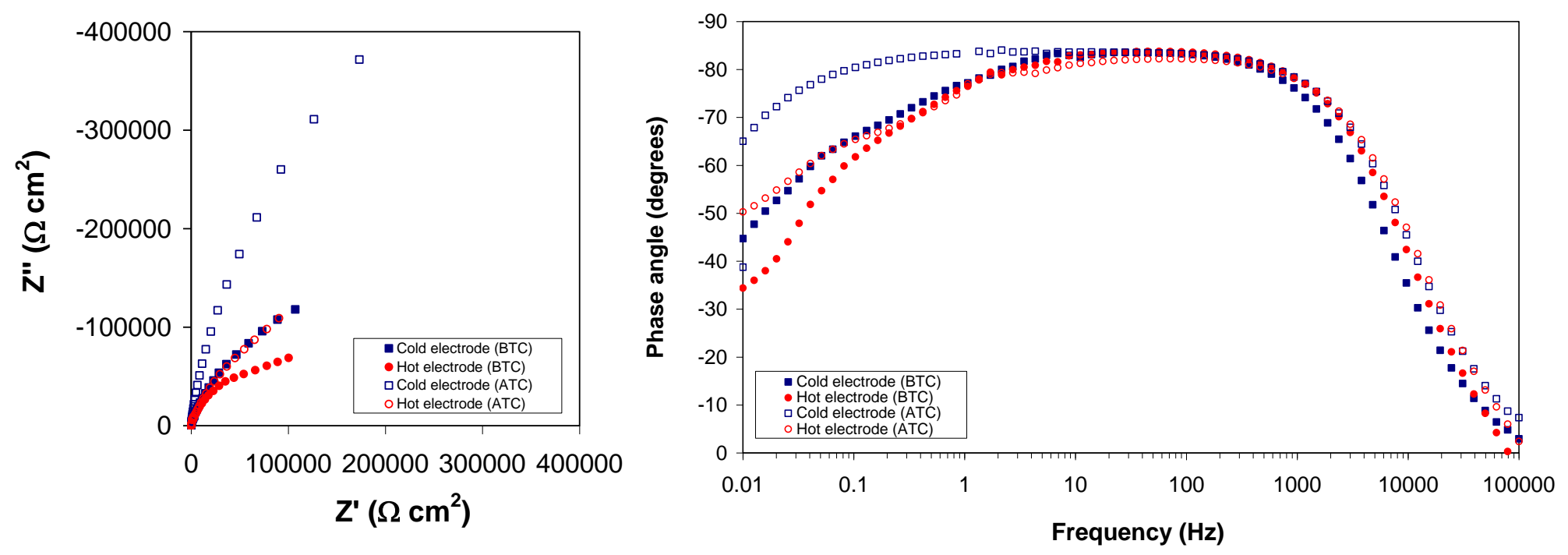

(b)
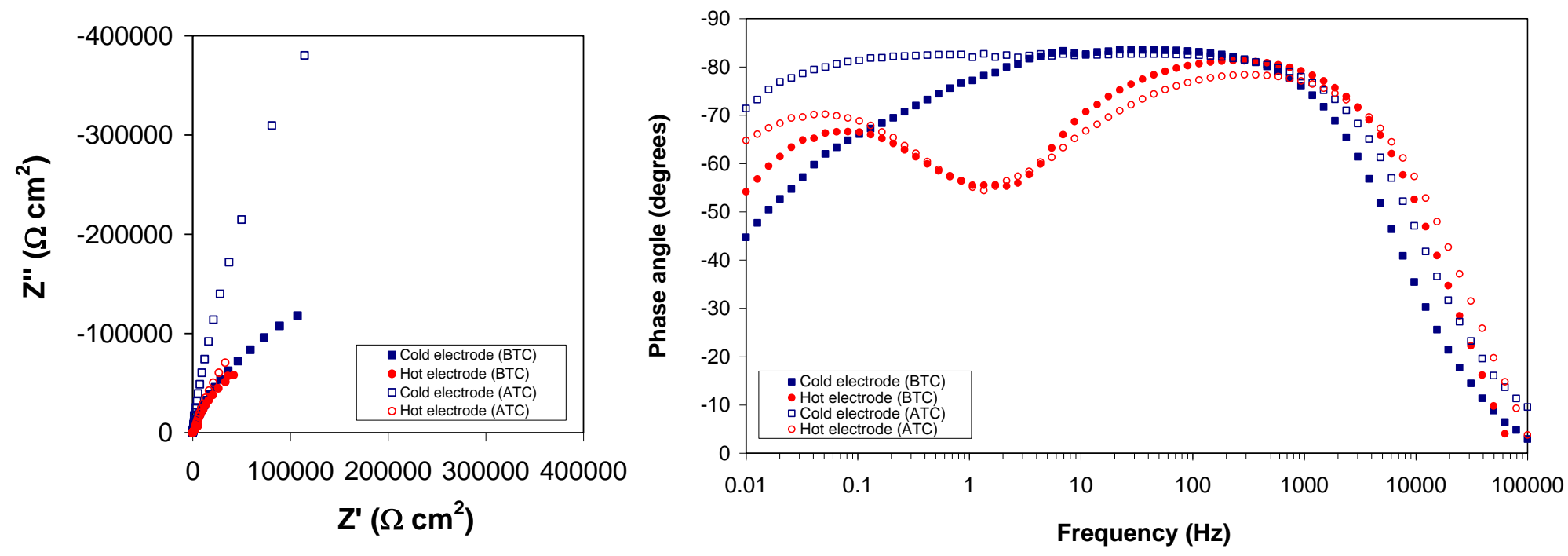

(c) 

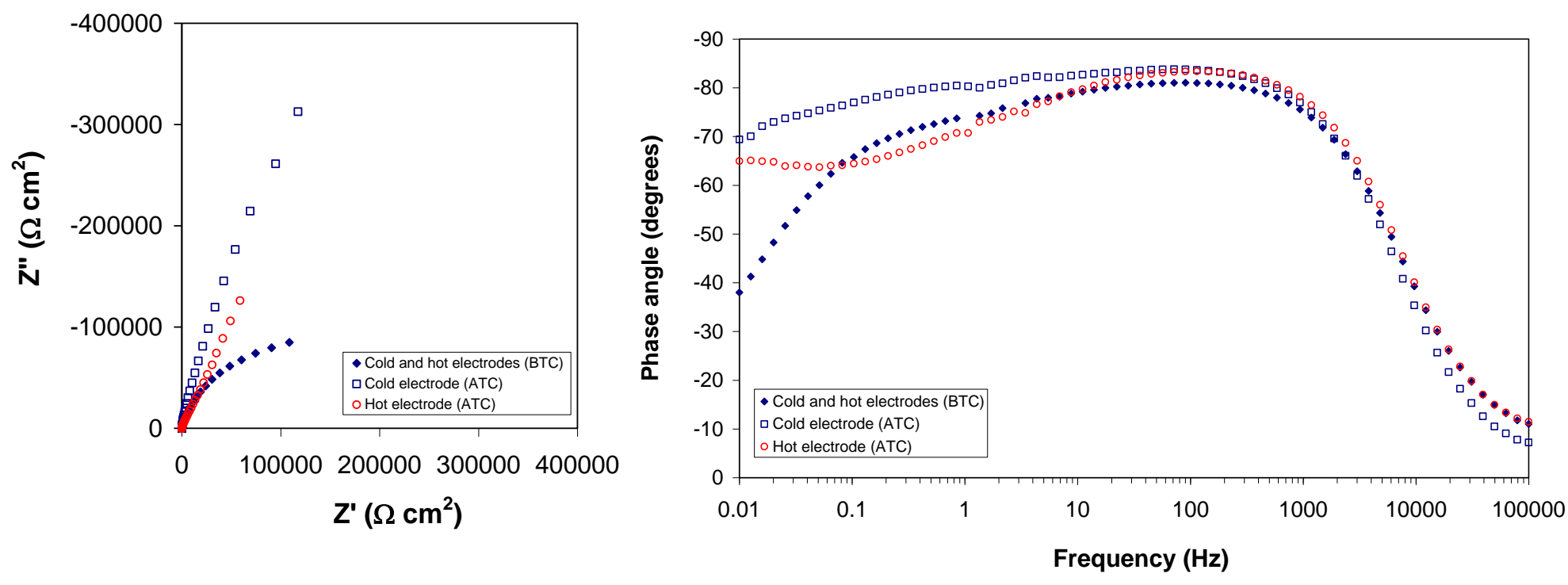

(a)
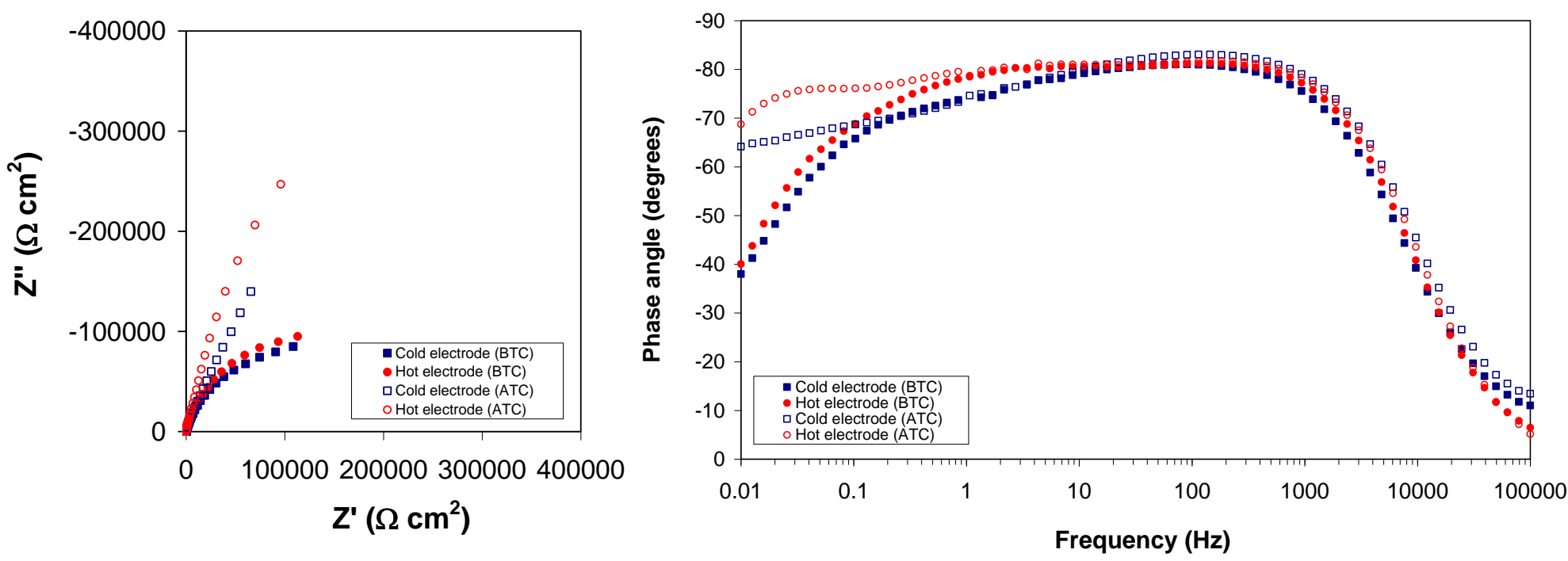

(b)
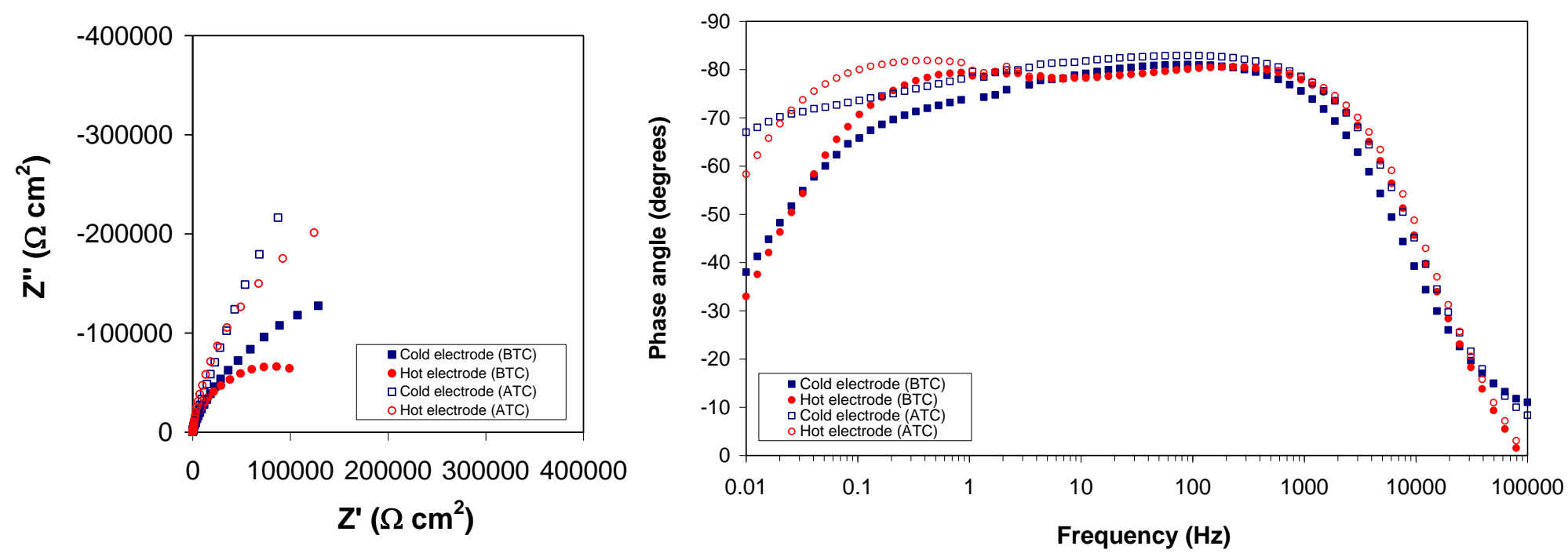

(c) 

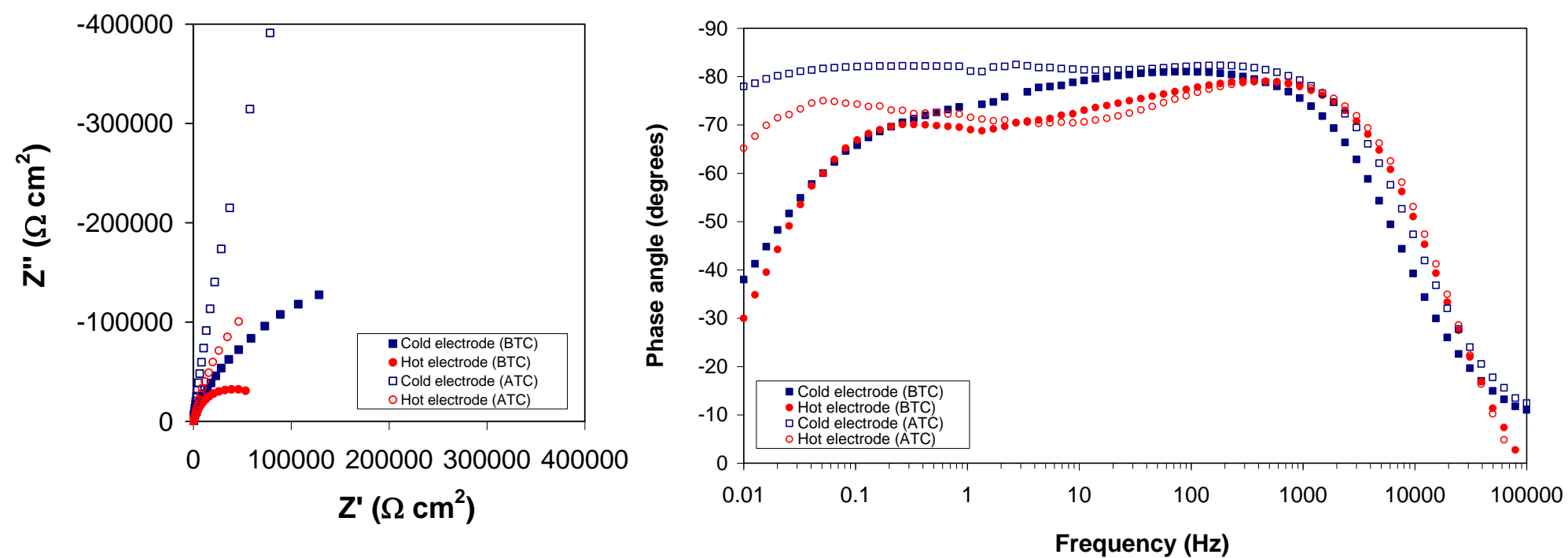

(d) 

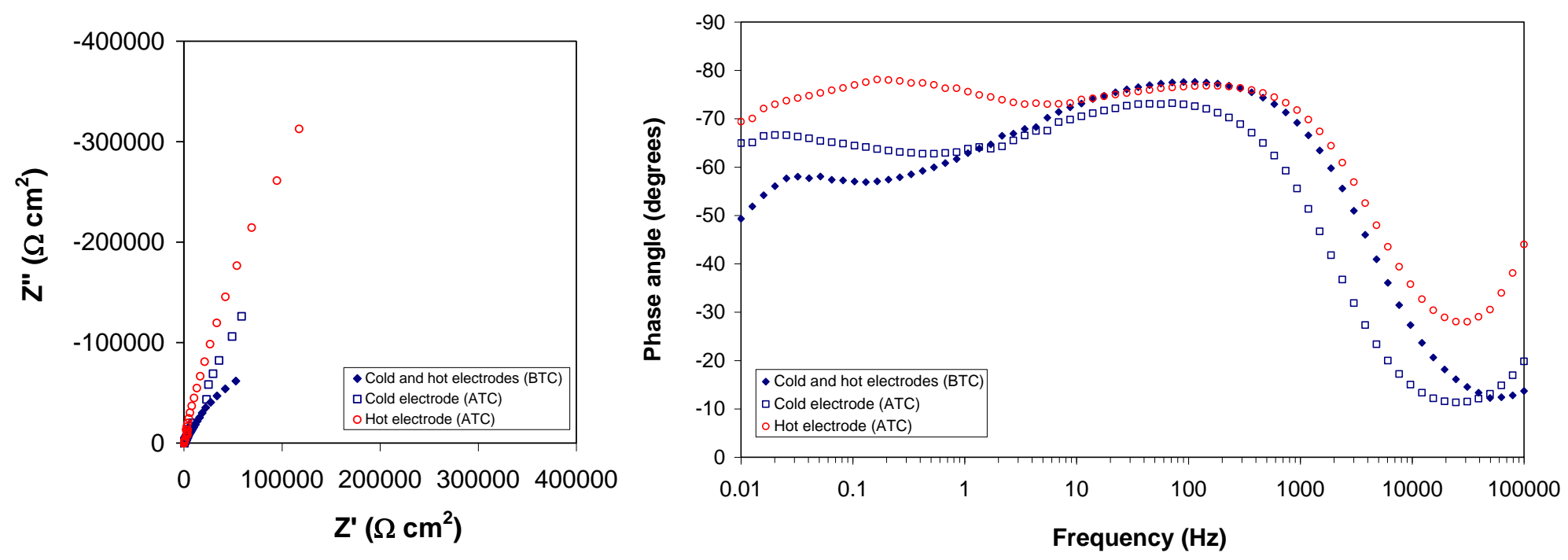

(a)
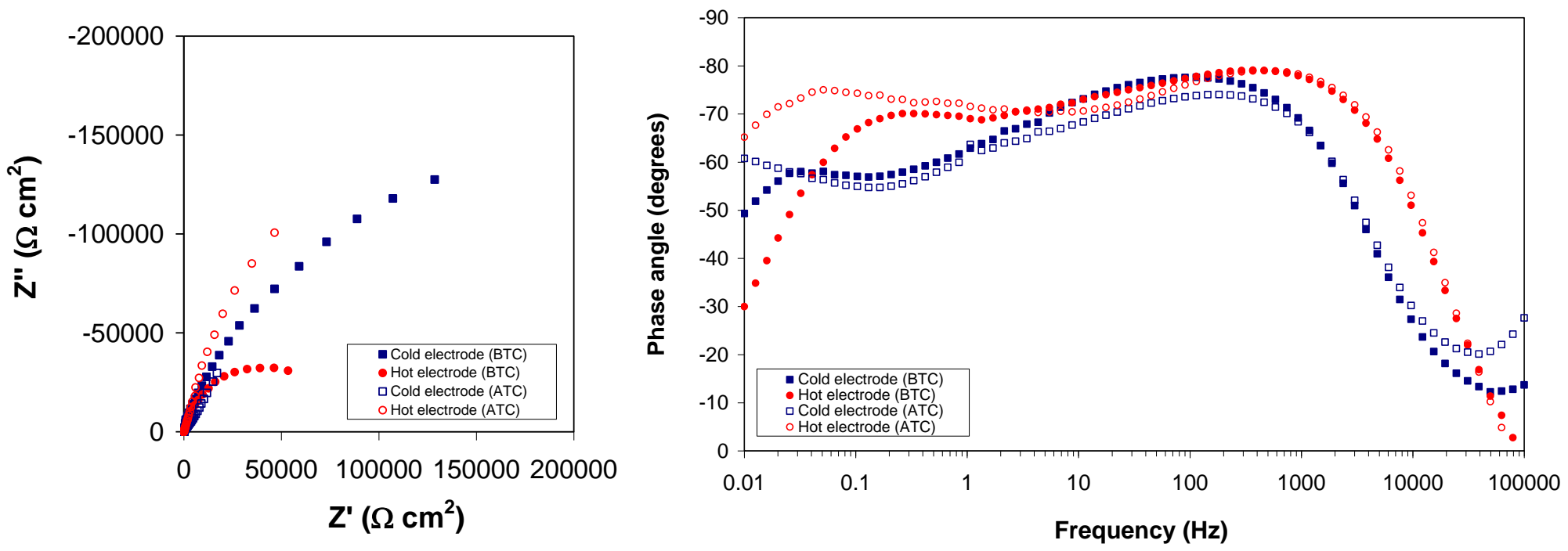

(b)
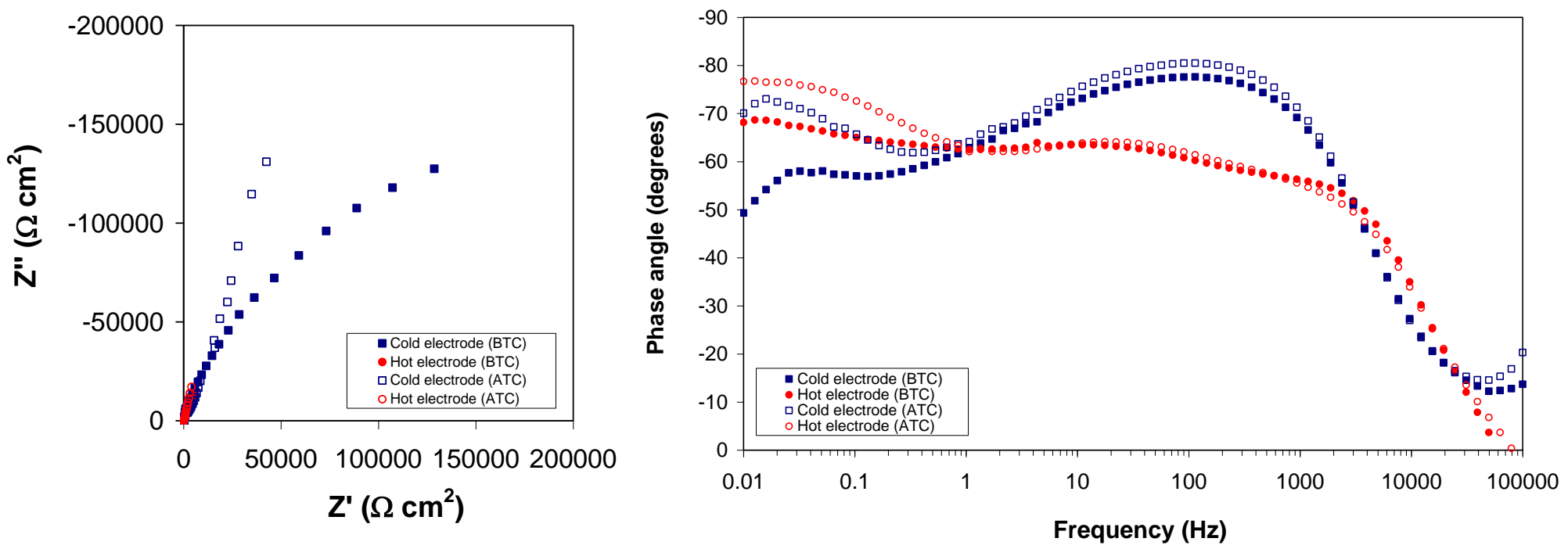

(c) 

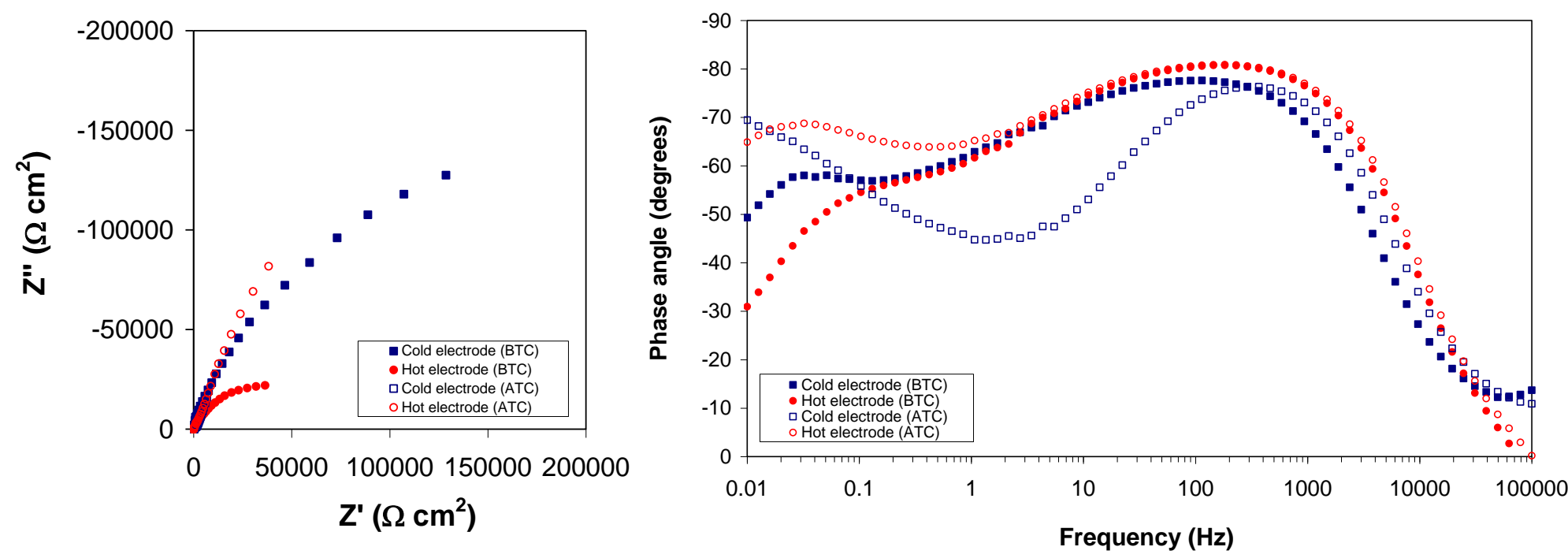

(d) 
Figure 9

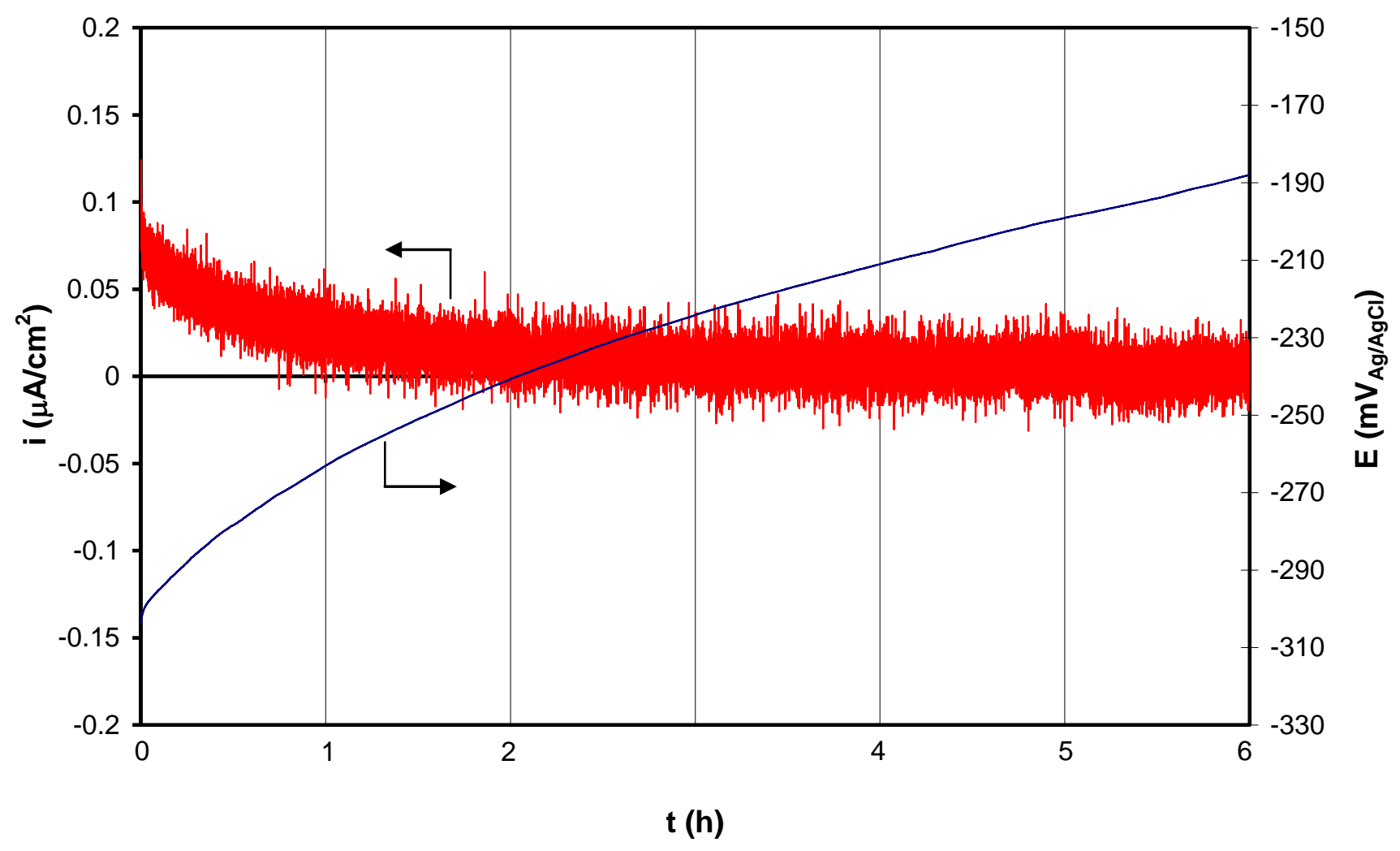




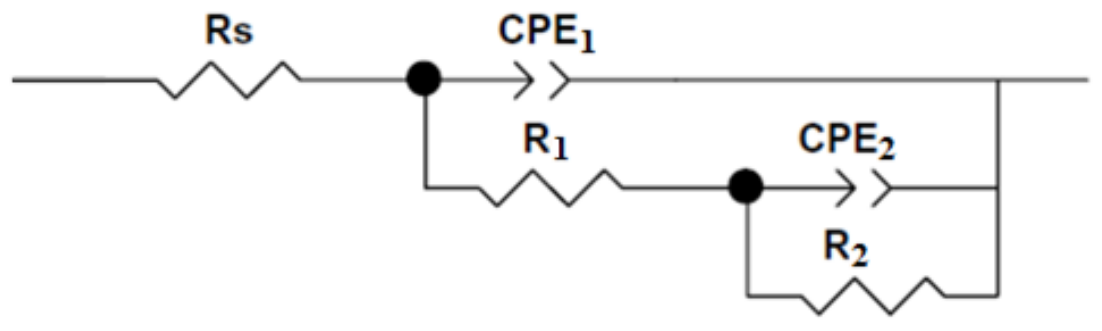

(a)
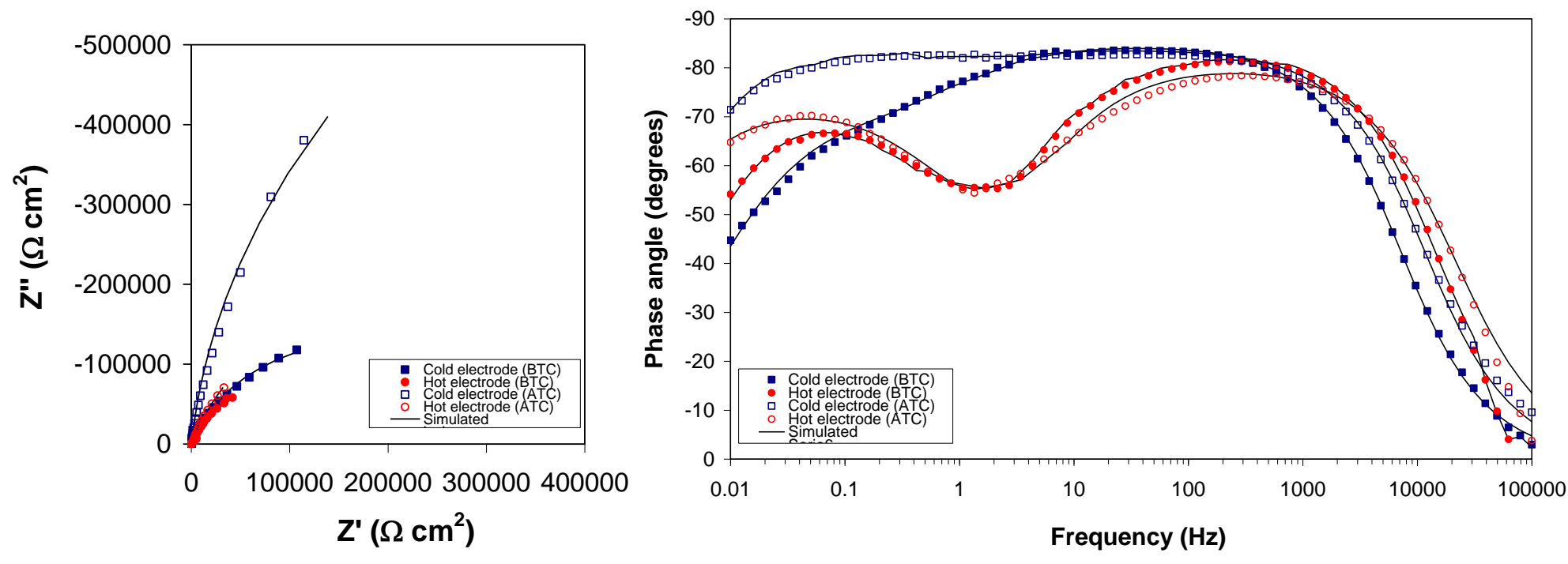

(b) 